\title{
DRAFT
}

\section{Determination of Turbine Blade Life from Engine Field Data}

\author{
Erwin V. Zaretsky, ${ }^{*}$ Jonathan S. Litt, ${ }^{\dagger}$ and Robert C. Hendricks \\ NASA Glenn Research Center, Cleveland, Ohio 44135 \\ and \\ Sherry M. Soditus $\$$ \\ United Airlines Maintenance, San Francisco, California 94128
}

\begin{abstract}
It is probable that no two engine companies determine the life of their engines or their components in the same way or apply the same experience and safety factors to their designs. Knowing the failure mode that is most likely to occur minimizes the amount of uncertainty and simplifies failure and life analysis. Available data regarding failure mode for aircraft engine blades, while favoring low-cycle, thermal mechanical fatigue as the controlling mode of failure, are not definitive. Sixteen high-pressure turbine (HPT) T-1 blade sets were removed from commercial aircraft engines that had been commercially flown by a single airline and inspected for damage. Each set contained 82 blades. The damage was cataloged into three categories related to their mode of failure: (1) Thermalmechanical fatigue, (2) Oxidation/Erosion, and (3) Other. From these field data, the turbine blade life was determined as well as the lives related to individual blade failure modes using Johnson-Weibull analysis. A simplified formula for calculating turbine blade life and reliability was formulated. The $L_{10}$ blade life was calculated to be 2427 cycles $(11077 \mathrm{hr})$. The resulting blade life attributed to oxidation/erosion equaled that attributed to thermalmechanical fatigue. The category that contributed most to blade failure was "Other." If there were there no blade failures attributed to oxidation/erosion and thermal-mechanical fatigue, the overall blade $L_{10}$ life would increase approximately 11 to 17 percent.
\end{abstract}

\section{Nomenclature}

$\boldsymbol{e} \quad=$ Weibull slope

$\boldsymbol{F} \quad=$ probability of failure, fraction or percent

$\boldsymbol{F}_{\mathbf{m}} \quad=$ mean probability of failure

$\boldsymbol{k}=$ life at operational condition, number of stress cycles or $\mathrm{hr}$

$\boldsymbol{L}=$ life, number of stress cycles or $\mathrm{hr}$

$\boldsymbol{L}_{\beta} \quad=$ characteristic life or life at which 63.2 percent of population fails, number of stress cycles or hr

$\boldsymbol{L}_{\mathbf{1 0}} \quad=10$-percent life or life at which 90 percent of a population survives, number of stress cycles or $\mathrm{hr}$

$\boldsymbol{L}_{\text {avg }} \quad=$ average life, total time divided by total number of components, number of stress cycles or $\mathrm{hr}$

$\boldsymbol{L}_{\mathbf{M}} \quad=$ mean time to removal

$\boldsymbol{L}_{\mathbf{m}} \quad=$ mean life of a population, number of stress cycles or $\mathrm{hr}$

$\boldsymbol{M} \quad=$ total number of stress cycles at operating condition where $\boldsymbol{M}=\boldsymbol{p m}$

$N=$ total number of engine operational condition changes over flight profile

$N_{\text {eng }}=$ total number of engines in overhaul in field data set

$\boldsymbol{m} \quad=$ number of stress cycles per interval

$\boldsymbol{n}=$ number of blades in a set

$n_{\text {blade }}=$ number of blade failures within a specified blade set of the population $N_{\text {eng }}$

$\boldsymbol{p} \quad=$ number of intervals

$\boldsymbol{S} \quad=$ probability of survival, fraction or percent

\footnotetext{
${ }^{*}$ Chief Engineer, Structures and Materials Division, 21000 Brookpark Road/Mail Stop 23-3, ASME Life Fellow.

${ }^{\dagger}$ Research Engineer, Controls and Dynamics Branch, 21000 Brookpark Road/Mail Stop 77-1, AIAA Member.

* Senior Technologist, Research and Technology Directorate, 21000 Brookpark Road/Mail Stop 5-9, AIAA Member and ASME Life Fellow.

${ }^{\S}$ Senior Staff Engineer, Powerplant Engineering, South Airport Boulevard. San Francisco, CA
} 


\section{DRAFT}

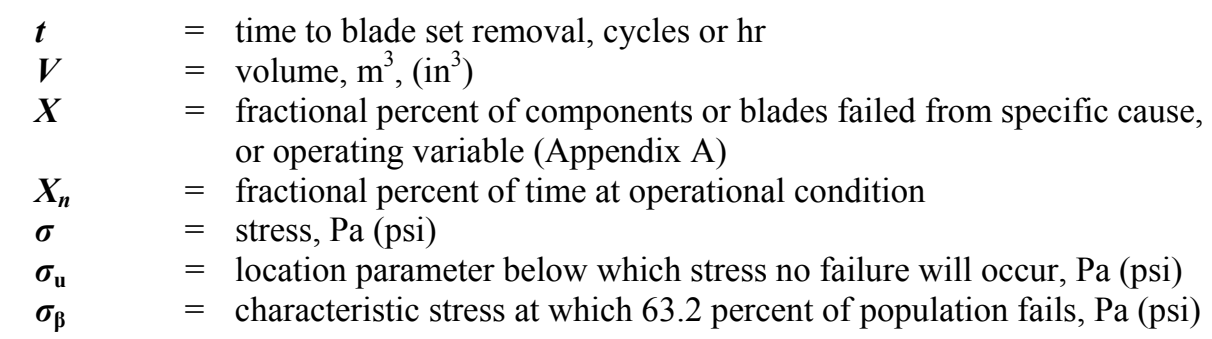

Subscripts:

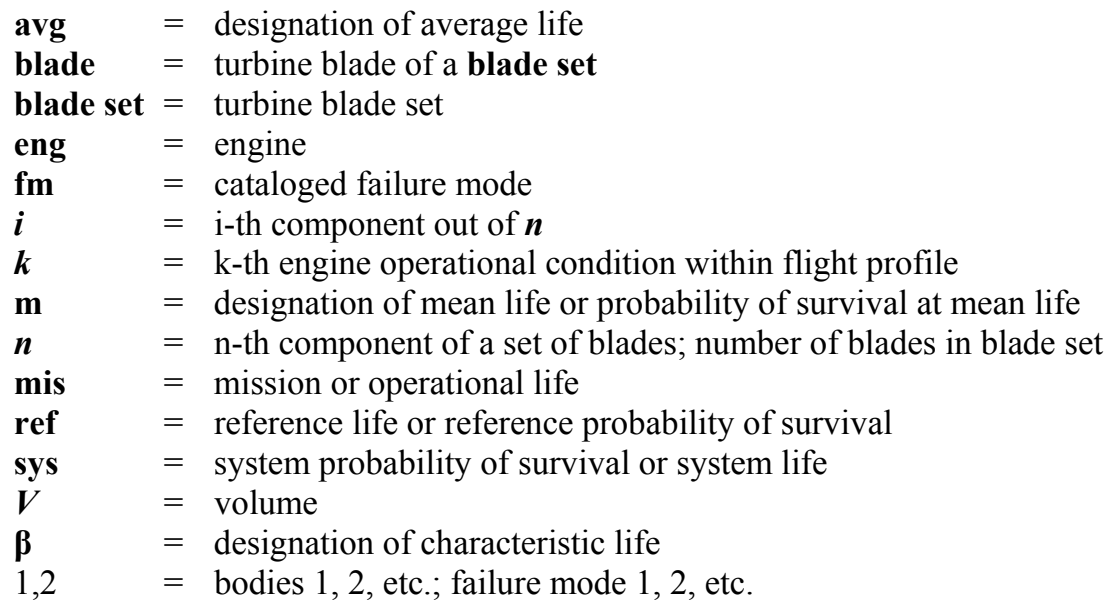

\section{Introduction}

HE service life of an aircraft gas turbine engine is based on deterministic calculations of low-cycle fatigue
and previous field experience with similar engines. It is probable that no two engine companies determine the life of their engines in the same way or apply the same experience and safety factors to their designs. ${ }^{1}$ Davis and Stearns $^{2}$ and Halila et al. ${ }^{3}$ discuss the mechanical and analytical methods and procedures for turbine engine and high-pressure turbine design. The designs of the engine components are based on life predictions by using material test curves that relate life in cycles or time (hrs.) as a function of stress. Six criteria for failure were presented: (1) Stress rupture; (2) Creep; (3) Yield (4) Low-cycle fatigue (LCF); (5) High-cycle fatigue (HCF); and (6) Fracture mechanics. Not mentioned as probable failure modes and/or cause for removal of rotating engine components in Refs. 2 and 3 are oxidation, corrosion, and erosion (wear).

Turbine blade metal temperatures frequently reach 1040 to $1090{ }^{\circ} \mathrm{C}\left(1900\right.$ to $\left.2000{ }^{\circ} \mathrm{F}\right)$, only a few hundred degrees below the melting point of the alloys used. Only because of oxidation-protective coatings and internal forced cooling is it possible for metals to be used under such harsh conditions. All commercial aircraft gas turbine engines use some form of nickel- or cobalt-base superalloy that has been intentionally strengthened and alloyed to resist high stresses in a high-temperature oxidizing environment. ${ }^{4}$ 


\section{DRAFT}

Aircraft engine turbine blades are not life-limited parts; that is, they can be used until they are no longer repairable, unlike limited life parts that must be removed after a specified amount of time or cycles, even if they appear new. The blades undergo regular inspections that result in no action, repair, or removal for cause. In this paper, a blade is considered failed when it is no longer fit for service and must be either repaired or replaced.

It is believed that the primary failure mechanism in turbine blades is thermal-mechanical fatigue (TMF). TMF cracks usually appear along the leading or trailing edge of the first-stage high-pressure turbine (HPT) T-1 blade. ${ }^{5}$ Also, because the turbine blades are exposed to highly corrosive and oxidizing combustion gases and the loss of metal by scaling, spalling, and corrosion can cause rapid failure.

Turbine blade materials have creep-rupture resistance to minimize creep failure at high speed and temperature for extended periods. Initially, the time to removal of these blades is determined by a creep criterion that is deterministic or is not assumed to be probabilistic. Material test data are used to predict rupture life based on calculated stress and temperature. This criterion is dependent on time exposure at stress and temperature. ${ }^{1}$

Blade coating life is another time-limiting criterion for removal and repair. The blades usually are removed when the engine is removed from service for other reasons, and, as necessary, the remaining coating is removed by chemical stripping or machining and is replaced. The coating life usually does not dictate blade replacement, only repair. ${ }^{1}$

Besides the time-life limitation of creep, the limiting time for blade replacement is high-cycle fatigue (HCF) life. As with low-cycle fatigue (LCF), HCF is probabilistic. The blades are subject to vibratory stresses combined with mechanical stresses from centrifugal loads, gas aerodynamic loads, and thermal loads. ${ }^{1}$

The failure modes for each blade in a turbine blade set are competitive. Knowing the blade failure mode that is most likely to occur minimizes the amount of uncertainty and simplifies failure and blade life analysis. Available data regarding failure mode, although favoring low-cycle, thermal-mechanical fatigue as the controlling mode of failure, are not definitive.

There are several other major contributors besides the competing failure modes that contribute to turbine blade set life uncertainty. First the data are quantal-response data. This means that the data are either censored on the left (before failure occurs) or censored on the right (failure has not occurred by a defined time). This situation arises when each blade is inspected only once and is determined to have failed or not failed. For turbine blade data, this 


\section{DRAFT}

type of information can be useful for reliability studies if the failed blades can be clustered by age (time to failure) at inspection (and the range of ages is large relative to the part life). ${ }^{6}$

In $1939, \mathrm{~W}$. Weibull ${ }^{7-9}$ is credited with being the first to suggest a reasonable way to estimate fracture strength with a statistical distribution function. He also applied the method and equation to fatigue data based on small sample (population) sizes. Leonard Johnson ${ }^{10}$ while with the GM Research Center in the 1950s and 60s is credited with coming up with a practical engineering analysis based on the Weibull distribution function. ${ }^{7-9}$ Johnson, using the Weibull distribution function to evaluate fatigue data, provides a means to evaluate censored data and to extract from these data the lives of the individual components that affect the system life.

In view of the aforementioned, it becomes the objectives of the work reported herein to (1) determine turbine blade life from turbine engine field data using Johnson-Weibull analysis, (2) determine the turbine blade life related to individual blade failure modes, and (3) provide a simplified formula for determining turbine blade life from field data for engine turbine blade sets.

\section{High-Pressure Turbine T-1 Blade Sets}

\section{A. Engine Operation and Repair}

When a new aircraft engine is introduced into an airline fleet, one of the first questions asked is what will be the average time (hr) between overhaul or refurbishment of the high-pressure turbine (HPT) T-1 blades. Typically, for a new engine program the airlines bring the engines in early for overhaul, for example, approximately at $10000 \mathrm{hr}$. As the airlines gain experience and confidence with an engine type, the time to refurbishment is increased for first-run engines, for example, at $22000 \mathrm{hr}$. After refurbishment, second-run engines probably get around $15000 \mathrm{hr}$ on the wing. The hot section is typically overhauled when the engine is removed from service. ${ }^{1}$

The typical hour-to-cycle ratio depends on the airline operator. Short-haul airline operation typically runs between 1 to less than $4 \mathrm{hr} /$ cycle. Long-haul, coast-to-coast airline operation in the continental United States typically runs between 4 to $6 \mathrm{hr} /$ cycle. For other airline operations, the average can be 6 to $13 \mathrm{hr} / \mathrm{cycle}$. These numbers play an important part in the overhaul process. It is expected that for the shorter cycle engines there will be more deterioration on the hot-section parts on the engines that have a shorter time cycle, implying that the deterioration is cycle dependent rather than time dependent. 


\section{DRAFT}

When an aircraft engine is removed from service for cause and shipped to the refurbishment shop, the engine and the performance of its individual module are evaluated and the root cause of removal determined. If the engine is removed for performance or hardware deterioration or major part failure, the engine will be, in most cases, completely broken down into modules: for example, compressor, turbine, auxiliary gearbox, and so forth. Each module will then be refurbished. ${ }^{1}$

\section{B. HPT T-1 Blades}

A photograph of the blade type studied in this report is shown in Fig. 1(a). The blade is made from a singlecrystal nickel-based alloy and plated using plasma vapor deposition (PVD) to provide oxidation and corrosion resistance. The blade material and coating chemistries are given in Table $1 .{ }^{11}$ The blade section is approximately $71 \mathrm{~mm}$ (2.8 in.) in height and has a cord length at the tip of approximately $37 \mathrm{~mm}$ (1.46 in.). The height from the blade root to the blade tip is approximately $118 \mathrm{~mm}(4.65 \mathrm{in}$.). The blade weighs approximately $277 \mathrm{~g}(0.611 \mathrm{lb})$. There are 82 blades in a $\mathrm{T}-1$ blade set for the particular engine application studied.
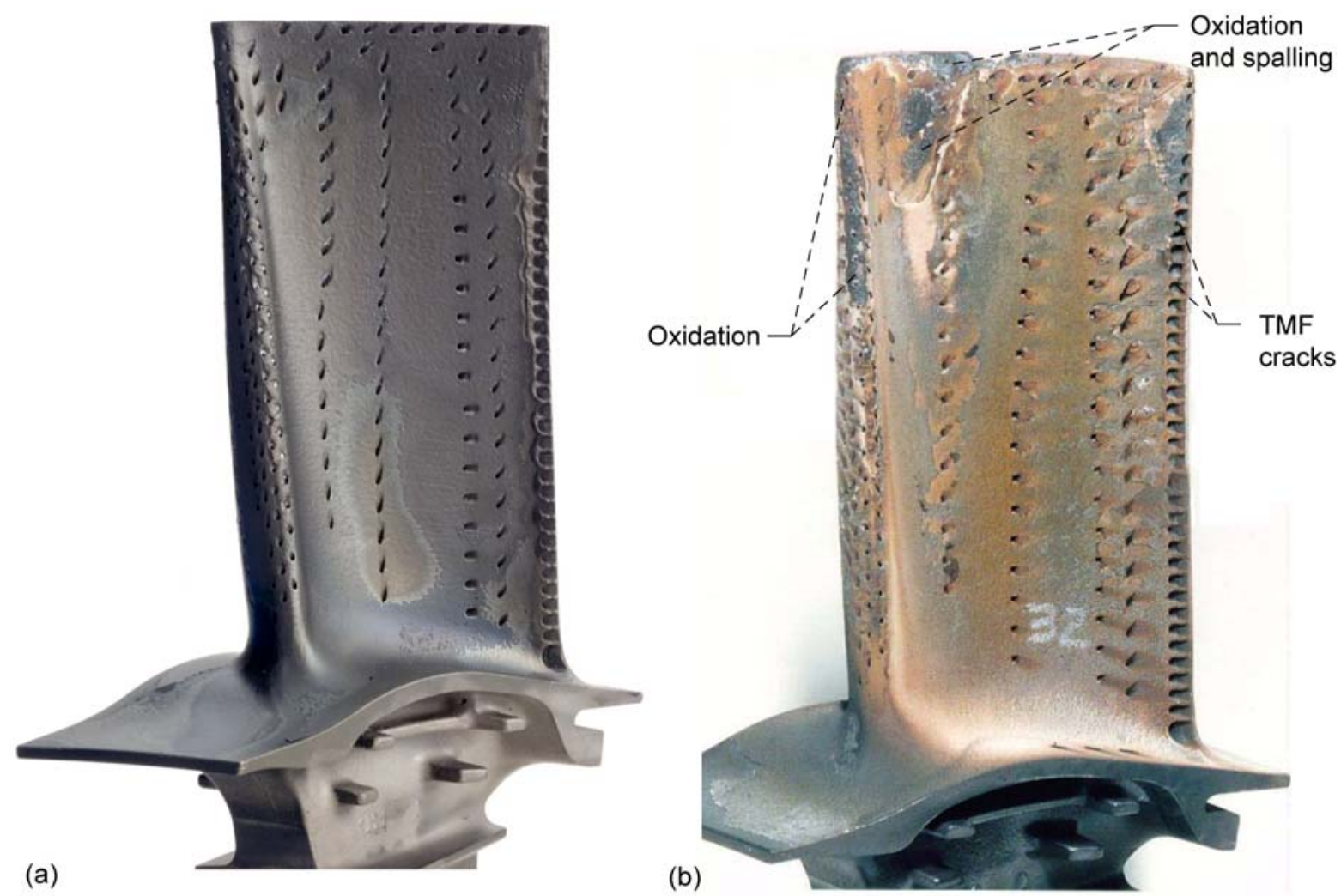

Figure 1. Comparison of unfailed and failed $T-1$ turbine blades used in study. (a) Example of unfailed T-1 turbine blade. (b) Example of failed T-1 turbine blade. 


\section{DRAFT}

Table 1. T-1 Turbine Blade Material Chemistry ${ }^{11}$

\begin{tabular}{|c|c|c|c|c|c|c|c|c|c|c|c|c|}
\hline \multicolumn{12}{|c|}{$\begin{array}{c}\text { Chemical element, } \\
\text { wt } \%\end{array}$} & \multirow{3}{*}{$\begin{array}{c}\begin{array}{c}\text { Density, } \\
\mathrm{kg} / \mathrm{m}^{3}\end{array} \\
\left.\left(\mathrm{lb} / \mathrm{in}^{3}\right)^{3}\right)\end{array}$} \\
\hline $\mathrm{Ni}$ & $\mathrm{Cr}$ & $\mathrm{Ti}$ & Mo & $\mathrm{W}$ & $\mathrm{Re}$ & $\mathrm{Ta}$ & $\mathrm{Al}$ & $\mathrm{Co}$ & $\mathrm{Hf}$ & $\mathrm{Si}$ & $\mathrm{Y}$ & \\
\hline Bal. & 5 & 0 & 2 & 6 & 3 & 8.7 & 5.6 & 10 & 0.1 & --- & --- & \\
\hline \multicolumn{13}{|c|}{ Overlay (coating) } \\
\hline $\mathrm{x} 1$ & $\mathrm{x} 3$ & --- & --- & --- & --- & --- & $\mathrm{x} 4$ & $\mathrm{x} 2$ & $\mathrm{x} 5$ & $\mathrm{x} 6$ & $\mathrm{x} 7$ & ---------- \\
\hline
\end{tabular}

A total of 82 blades is inserted around a T-1 turbine disk. The resulting tip-to-tip diameter of the blades is approximately $0.93 \mathrm{~m}(36.5 \mathrm{in}$.). The blades are spun at a speed of approximately $9126 \mathrm{rpm}$ during cruise, or 84.5 percent of the maximum speed of $10800 \mathrm{rpm}$. Loading on the blades is due to centrifugal load, thermal loads from heating of the blades, aerodynamic loads from impingement of the hot combustion gases against the blade, and vibratory loads due to blade rotation. A load and stress analysis of these blades was beyond the scope of this paper.

An engine is borescoped periodically to determine its health. It is not uncommon to find that the HPT blades deteriorate in service because of the extreme operating conditions they encounter. Even when an engine is operating properly, it can experience some form of hardware deterioration of the high-pressure turbine (HPT) T-1 blades. Such a failed blade is shown in Fig. 1(b). At the time of removal this blade had run $15000 \mathrm{hr}$ (2700 cycles). The condition is typical for this time period.

\section{Blade Failure Criteria.}

For the purpose of this report, blade failure is defined as the blade being no longer fit for its intended purpose but still capable of functioning for a limited time until being removed from service. Depending on the condition of the deterioration, an engine may be allowed to remain in service on a decreased-cycle inspection interval until it is determined that the deterioration is beyond limits (or its exhaust gas temperature (EGT) margin is too small) and the engine must be removed from service. ${ }^{1}$ Causes of blade failure and/or removal are as follows:

1. Creep (Stress rupture)

2. Yield

3. Thermal-mechanical fatigue (TMF)

a. Low-cycle fatigue (LCF)

b. High-cycle fatigue (HCF) 


\section{DRAFT}

4. Fracture mechanics (flaw initiated crack)

5. Fretting (wear and fatigue)

6. Oxidation

7. Corrosion

8. Erosion (wear)

9. Foreign object damage (FOD)

10. Wear (blade tip rub)

For post-operation failure inspection of blade sets, the blade failures were cataloged under three categories:

1. Thermal-mechanical fatigue

2. Oxidation/Erosion

3. Other (creep, yield, fracture mechanics, fretting, corrosion, FOD, and wear )

The blades removed from service can generally be repaired or refurbished two or more times. The blades can be stripped of their coatings and recoated. There is a minimum wall thickness and aerodynamic shape that must be met before the blade can be recoated. They can have minor blend repairs and new abrasive tips installed, and the roots can be shot peened. Of those $\mathrm{T}-1$ blades that are scrapped, approximately 90 percent are due to under-platform stress corrosion.

\section{Procedure}

Sixteen high-pressure turbine (HPT) T-1 blade sets were removed from commercial aircraft engines that had been commercially flown by a single airline. These engines were brought to the maintenance shop for refurbishment or overhaul. The blades on each HPT T-1 blade set were removed and inspected for damage. The damage was cataloged into three categories related to their mode of failure:

1. Thermal-mechanical fatigue (TMF)

2. Oxidation/Erosion $(\mathrm{O} / \mathrm{E})$ 


\section{DRAFT}

\section{Other $(\mathrm{O})$}

The technician had a preset order in which to look for failure modes. The blades were first inspected for thermalmechanical fatigue (TMF). If cracks were evident on the blade, and even if other failure modes were also evident, the cause for removal was cataloged as TMF. The blades not failed from TMF were inspected for oxidation/erosion $(\mathrm{O} / \mathrm{E})$. As with those blades cataloged as being failed by TMF, those blades that exhibited $\mathrm{O} / \mathrm{E}$ damage were so cataloged even where damage from other failure modes were manifested on the blade. The blades not failed for TMF or O/E were examined for damage for the other causes discussed previously. These other causes were not separately identified and were categorized and cataloged as "Other."

A list of the engine blade sets, their time at removal, their respective number of failures, and their failure modes are given in Table 2. Of a total of 1312 blades contained in the $N_{\text {eng }}=16$ blade sets, 111 were considered to have failed, or approximately 8.5 percent of the population. Although each of these blade sets were to have been comprised of all new blades when installed in the engine, three blade sets had a mix of new blades with previously run (older) blades. The failures that were reported for the mixed blade sets did not distinguish between the older and newer blades.

Table 2. Data Set for T-1 Turbine Blade Sets Including Estimated Time to First Blade Failure in a Set and Causes of Failure [Number of Turbine Blades in Set, 82]

\begin{tabular}{|c|c|c|c|c|c|c|c|}
\hline \multirow[t]{3}{*}{$\begin{array}{l}\text { Engine } \\
\text { number }\end{array}$} & \multicolumn{2}{|c|}{$\begin{array}{c}\text { Time of removal } \\
\text { of blade set }\end{array}$} & \multirow{3}{*}{$\begin{array}{l}\text { Number } \\
\text { of } \\
\text { failures }\end{array}$} & \multicolumn{3}{|c|}{ Observed failure mode } & \multirow{3}{*}{$\begin{array}{c}\text { Estimated time } \\
\text { to first blade } \\
\text { failure, } \\
\text { cycles } \\
\end{array}$} \\
\hline & \multirow[t]{2}{*}{$\mathrm{hr}$} & \multirow[t]{2}{*}{ cycles } & & Oxidation/erosion & Thermal/mechanical & Other & \\
\hline & & & & \multicolumn{3}{|c|}{ Number of blades failed } & \\
\hline $1 \mathrm{~B}$ & 5898 & 1327 & 1 & --- & --- & 1 & 1327 \\
\hline $2 \mathrm{~B}$ & 7318 & 1404 & 5 & 3 & 2 & --- & 1017 \\
\hline $3 \mathrm{~B}$ & 8188 & 1675 & 2 & --- & --- & 2 & 1443 \\
\hline 4B & a 8333 & 1747 & 3 & --- & 1 & 2 & 1391 \\
\hline $5 \mathrm{~B}$ & 9049 & 1827 & 4 & 3 & --- & 1 & 1379 \\
\hline $6 \mathrm{~B}$ & 8717 & 1843 & 41 & --- & 1 & 40 & 886 \\
\hline $7 \mathrm{~B}$ & 9600 & 1924 & 10 & --- & 10 & --- & 1228 \\
\hline $8 \mathrm{~B}$ & 10113 & 2043 & 4 & 1 & 1 & 2 & 1542 \\
\hline $9 B$ & 7770 & 2047 & 7 & 7 & --- & --- & 1394 \\
\hline $10 \mathrm{~B}$ & 10675 & 2091 & 2 & --- & --- & 2 & 1801 \\
\hline $11 \mathrm{~B}$ & 7690 & 2115 & 4 & 1 & 1 & 2 & 1596 \\
\hline $12 \mathrm{~B}$ & 11051 & 2175 & 2 & --- & 1 & 1 & 1873 \\
\hline 13B & 10398 & 2184 & 12 & 4 & --- & 8 & 1348 \\
\hline $14 \mathrm{~B}$ & 11614 & 2292 & 5 & 1 & 1 & 3 & 1660 \\
\hline $15 \mathrm{~B}$ & 10238 & 2295 & 3 & 3 & --- & --- & 1827 \\
\hline $16 \mathrm{~B}$ & 14083 & 2847 & 6 & --- & 4 & 2 & 1994 \\
\hline \multicolumn{3}{|l|}{ Total } & 111 & 23 & 22 & 66 & \\
\hline$L_{\text {avg }}$ & 9421 & 1990 & & & & & 1482 \\
\hline
\end{tabular}

${ }^{\mathrm{a}}$ Estimated 


\section{DRAFT}

Ideally, the time to failure for each blade in a set should be known. More specifically, the time at which the first blade fails in a set should be known based on the assumption that at the time of the first failure, the entire set is no longer fit for its intended purpose. For these type data, these times are not available and will have to be estimated. However, once the time to first failure in a set is determined or estimated, the distributive lives of the blades can be determined as well as the resulting lives from each failure mode.

\section{Statistical Analysis}

\section{A. Weibull Analysis}

In 1939, W. Weibull ${ }^{8,9}$ is credited with being the first to suggest a reasonable way to estimate fracture strength with a statistical distribution function. He also applied the method and equation to fatigue data based on small sample (population) sizes. The probability distribution function identified by Weibull is as follows:

$$
\ln \ln \left(\frac{1}{\boldsymbol{S}}\right)=\boldsymbol{e} \ln \left(\frac{\boldsymbol{L}}{\boldsymbol{L}_{\boldsymbol{\beta}}}\right) \quad \text { where } 0<\boldsymbol{L}<\infty ; 0<\boldsymbol{S}<1
$$

This form of Eq. (1) is referred to as the 2-parameter Weibull distribution function. The derivation of this equation is given in Ref. 12, and in Appendix A.

The variable $\boldsymbol{S}$ is the level of survivability being considered. For example, if 15 percent of the samples have failed, then the survivability would be $0.85 . \boldsymbol{L}$ is the life in cycles or hours at which the fraction $(1-\boldsymbol{S})$ of samples have failed. In the case of $\boldsymbol{S}$ equaling 0.9 (90 percent), $\boldsymbol{L}$ is the life at which 10 percent of the samples have failedtypically referred to as the $\boldsymbol{L}_{\mathbf{1 0}}$ life. $\boldsymbol{L}_{\beta}$ is the characteristic life of the material, defined as the life at which 63.2 percent of the samples have failed. Finally, $\boldsymbol{e}$ is the Weibull parameter or slope, which is an indicator of the scatter or distribution in the data - the larger the slope, the smaller the amount of scatter.

When plotting the $\ln \ln [1 / \boldsymbol{S}]$ as the ordinate against the $\ln \boldsymbol{L}$ as the abscissa, fatigue data are assumed to plot as a straight line (Fig. 2). The ordinate $\ln \ln [1 / \boldsymbol{S}]$ is graduated in statistical percent of components failed or removed for cause as a function of $\ln \boldsymbol{L}$, the natural $\log$ of the time or cycles to failure. The tangent of the line is the Weibull parameter or slope $\boldsymbol{e}$, which is indicative of the shape of the cumulative distribution or the amount of scatter of the data. A Weibull slope $\boldsymbol{e}$ of 1.0 is indicative of an exponential distribution of the data, 2.0 is a Rayleigh distribution, 


\section{DRAFT}

and 3.57 is approximately that of a normal distribution of data. For convenience, the ordinate is graduated as the "statistical percent of components failed."

There are many examples of the use of the Weibull distribution function to determine the life and strength of materials, structural components, and machines. The first use of the Weibull distribution function outside of W. Weibull's original reported work $^{8,9}$ was by G. Lundberg and A. Palmgren ${ }^{13}$ for predicting the life of ball and roller bearings.

Burrow et al. $^{14}$ used Weibull analysis to determine the reliability of tensile strength measurements on dental restorative

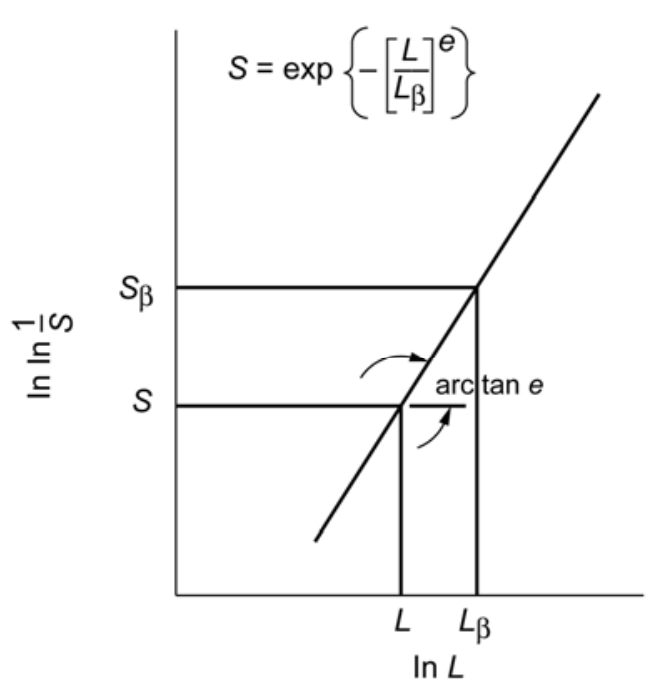

Figure 2. Generic Weibull plot where (Weibull) slope of line is $e$; probability of survival, $S_{\beta}$, is 36.8 percent at which $L=L_{\beta}$ or $L / L_{\beta}=1$.

materials. Ellis and Tordonato ${ }^{15}$ used Weibull analysis in their failure analysis and life assessment studies of boiler tubes. The fatigue life associated with corrosion fatigue cracking of welded tubing was predicted.

Tomimatsu et al. ${ }^{16}$ used Weibull analysis in their determination of the fracture toughness of two steels used in reactor pressure vessel fabrication. Weibull analysis and dynamic fatigue slow-crack-growth parameters were used by Osborn et al. ${ }^{17}$ to demonstrate a significant difference in the high-temperature behavior of two silicon nitrides (SN-88 and NT164). Ostojic and Berndt ${ }^{18}$ demonstrated that Weibull parameters such as slope and characteristic life were meaningful parameters when determining the variability of bond strengths of thermally sprayed coatings.

Holland and Zaretsky ${ }^{19}$ used Weibull statistics to determine the fracture strength of two different batches of cast A357-T6 aluminum. The mean fracture strengths for the two batches were found to differ by an insignificant 1.1 percent. However, using a Weibull analysis they determined at the 99.9999 percent probability of survival (one failure in a million) that the actual fracture strengths differed by 14.3 percent.

Weibull analysis can also be used to evaluate preventive maintenance practices. Williams and $\mathrm{Fec}^{20}$ studying reconditioned railroad roller bearings determined with Weibull analysis that the current practice of inspecting bearings at 200,000 miles was an acceptable practice. Summer-Smith ${ }^{21}$ applied Weibull analysis to the service life obtained from maintenance records that identified the cause of failure of a hydrodynamically lubricated thrust bearing and a rolling-element bearing, and increased production reliability. Similarly, Vlcek et al. ${ }^{22}$ used Weibull analysis to rank the relative fatigue lives of PVC coatings used in a printing process. The fatigue life of one PVC 


\section{DRAFT}

coating over another was demonstrated using $\boldsymbol{L}_{\mathbf{1 0}}$ lives, and the ratio of the $\boldsymbol{L}_{\mathbf{1 0}}$ life of a developed PVC coating to the original was found to be 2.3 .

The method of using the Weibull distribution function for data analysis for determining component life and reliability was developed and refined by Johnson. ${ }^{10}$ The Johnson ${ }^{10}$ method was used to analyze the data reported herein.

\section{B. Strict-Series System Reliability Blade Life}

System life prediction or the life of a single blade set can be determined using "strict-series system reliability" derived in Appendix B. ${ }^{12,23}$ The reliability (or probability of survival), $\boldsymbol{S}$, and the probability of failure, $\boldsymbol{F}$, are related by $\boldsymbol{F}=(1-S)$. For a given time or blade set life, the reliability of an individual blade set $\boldsymbol{S}_{\mathrm{sys}}$ of independent blades making up the blade set is the product of the independent reliabilities of each individual blade in the blade set $\boldsymbol{S}_{\boldsymbol{i}}(i=$ $1,2, \ldots, \boldsymbol{n})$, as shown in Eq. (2):

$$
S_{\text {sys }}=S_{1} \times S_{2} \times \cdots \times S_{n}
$$

Where $\boldsymbol{S}_{\mathrm{sys}}$ is the blade set reliability, and $\boldsymbol{S}_{1}, \boldsymbol{S}_{2} \ldots \boldsymbol{S}_{n}$ is the reliability of each blade in the blade set. If all components have the same reliability $\boldsymbol{S}_{1}=\boldsymbol{S}_{2} \ldots=\boldsymbol{S}_{\boldsymbol{n}}$ (as is assumed here), then Eq.(2) reduces to

$$
S_{\mathrm{sys}}=S_{n}^{n}
$$

Where $\boldsymbol{n}$ is the number of blades in the blade set. For our case, each engine blade set has a total of 82 blades. Thus, for one blade set, Eq. (3) can be written as

$$
S_{\text {sys }}=S_{n}^{82}
$$

From Eq. (2), the lives of each of the blades at a specified reliability can be combined to determine the calculated system $\boldsymbol{L}_{\text {sys }}$ life of the set using the two-parameter Weibull distribution function (Eq. (1)) for the blades comprising the system and strict-series system reliability ${ }^{13}$ as follows:

$$
\frac{1}{\boldsymbol{L}_{\mathrm{sys}}^{\boldsymbol{e}}}=\left(\frac{1}{\boldsymbol{L}_{1}^{\boldsymbol{e}_{1}}}+\frac{1}{\boldsymbol{L}_{2}^{\boldsymbol{e}_{2}}}+\cdots \frac{1}{\boldsymbol{L}_{n}^{\boldsymbol{e}_{n}}}\right)
$$




\section{DRAFT}

where $\boldsymbol{L}_{\text {sys }}$ is the life of individual blade set and $\boldsymbol{L}_{1}, \boldsymbol{L}_{2} \ldots \boldsymbol{L}_{\boldsymbol{n}}$ are the lives of the individual blades. The derivation for Eq. (5) is given in Appendix B. ${ }^{12}$

In this work, the 82 blades in a set are each assumed to have the same life, $\boldsymbol{L}$, where $\boldsymbol{L}_{1}=\boldsymbol{L}_{2}=\ldots=\boldsymbol{L}_{\boldsymbol{n}}$ and Weibull slope, $\boldsymbol{e}=\boldsymbol{e}_{1}=\boldsymbol{e}_{2}=\ldots=\boldsymbol{e}_{\boldsymbol{n}}$. Accordingly, Eq. (5) can be written for the 82 blades in a single blade set as

$$
\frac{1}{\boldsymbol{L}_{\mathrm{sys}}^{\boldsymbol{e}_{\boldsymbol{n}}}}=\left(\frac{82}{\boldsymbol{L}^{\boldsymbol{e}_{\boldsymbol{n}}}}\right)
$$

The calculated system life is dependent on the resultant value of the system Weibull slope $\boldsymbol{e}$.

\section{Linear Damage Rule}

The blade set life is calculated using Eq. (6) for each operating condition of its engine operating profile. In Appendix C is a representation of a short-duration flight profile (Fig. C.1). In order to obtain the operational life of the blade set, the resulting system lives for each of the operating conditions (illustrated in Fig. C.1) are combined in Eq. (7) using the linear damage (Palmgren-Langer-Miner) rule discussed in Appendix $C^{24-27}$ where $\boldsymbol{L}_{\mathbf{s y s}_{\boldsymbol{k}}}$ is the life for condition $\boldsymbol{k}$ and $\boldsymbol{X}_{\boldsymbol{k}}$ is the time fraction spent at condition $\boldsymbol{k},(\boldsymbol{k}=1,2, \ldots \boldsymbol{N})$.

$$
\frac{1}{L_{\text {mis }}}=\frac{X_{1}}{L_{\mathrm{sys}_{1}}}+\frac{X_{2}}{L_{\mathrm{sys}_{2}}}+\cdots \frac{X_{k}}{L_{\mathrm{sys}_{k}}} \ldots+\frac{X_{N}}{L_{\mathrm{sys}_{N}}}
$$

It is assumed that each of the blade sets in Table 2 have the same operational cycle. $\boldsymbol{N}=16$ changes in engine operational conditions over the flight profile for Fig. C.1. (Operational cycle $N$ is not to be confused with $N_{\text {eng }}$, the number of engine overhaul blade repairs of Table 2, which also has 16 entries). The most damaging condition is at take-off (TO) with the Cruise condition being the dominate time on the engine.

\section{Results and Discussion}

Sixteen high-pressure turbine (HPT) T-1 blade sets $\left(\boldsymbol{N}_{\text {eng }}=16\right)$ were removed from commercial aircraft engines that had been commercially flown by a single airline. These engines were brought to the maintenance shop for refurbishment or overhaul. The blades for these turbines were manufactured from a single-crystal nickel alloy whose chemical composition together with the chemical composition of the blade coating are given in Table 1 . The blades 


\section{DRAFT}

on each HPT T-1 blade set were removed and inspected for damage. The damage was cataloged in three categories related to their mode of failure:

1. Thermal-mechanical fatigue (TMF)

2. Oxidation/Erosion $(\mathrm{O} / \mathrm{E})$

3. Other $(\mathrm{O})$ (creep, yield, fracture mechanics, fretting, corrosion, FOD, and wear )

The blades were first inspected for thermal-mechanical fatigue (TMF). If cracks were evident on the blade even if other failure modes were also evident, the cause for removal was cataloged as TMF. The remaining blades were inspected for oxidation/erosion $(\mathrm{O} / \mathrm{E})$. As with those blades cataloged as being failed by TMF, those blades that exhibited $\mathrm{O} / \mathrm{E}$ damaged were so cataloged even where damage from other failure modes were manifested on the blade. The remaining blades were examined for damage for the other causes. These other causes were not identified and categorized and cataloged as "Other." The time of removal of the blade sets together with the cataloged failure mode of those blades in each set that failed is summarized in Table 2.

\section{Field Data Analysis}

Weibull plots of these data for $N_{\text {eng }}=16$ based on the time of removal in flight hours and flight cycles are shown in Fig. 3. 


\section{DRAFT}
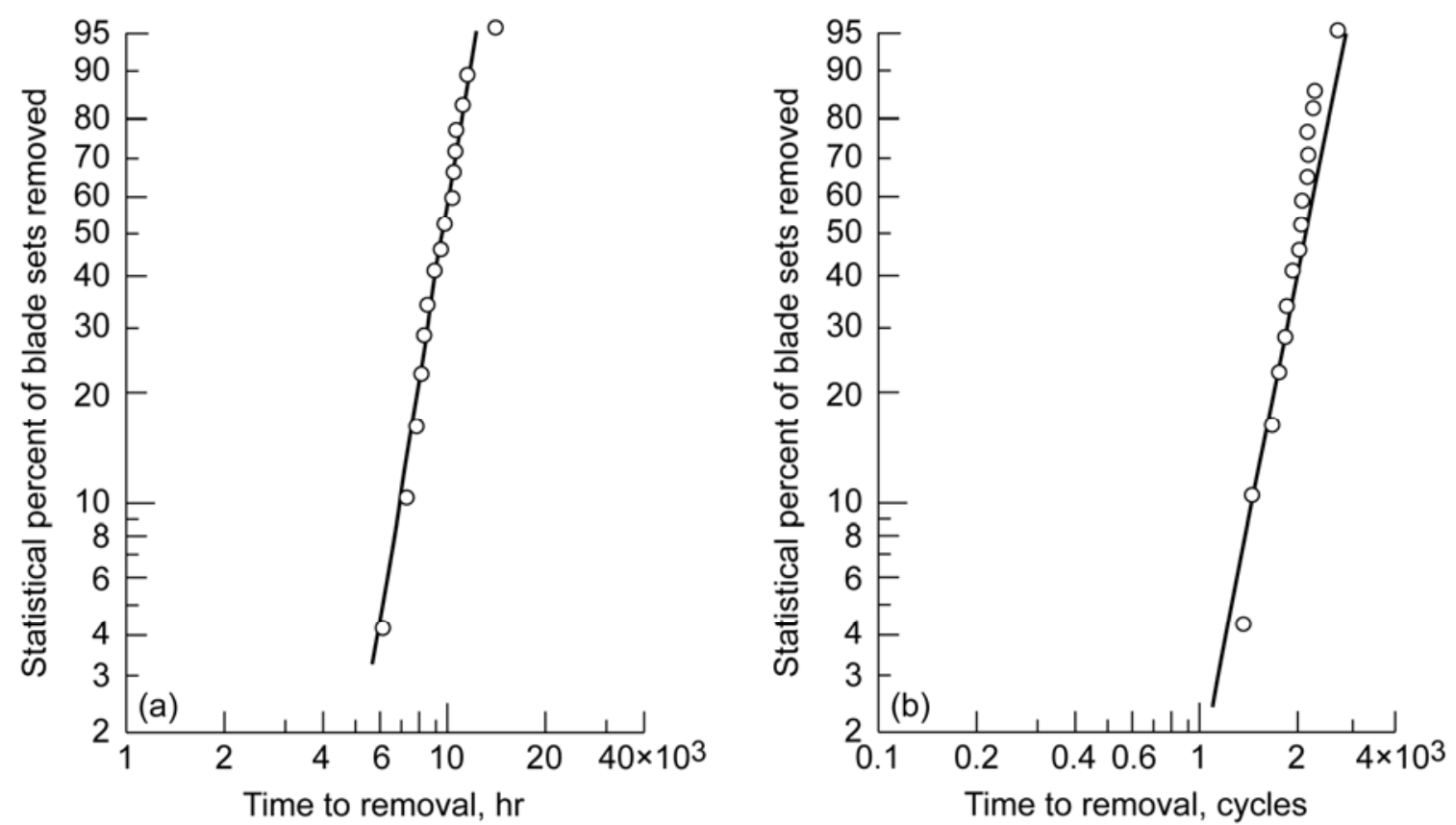

Figure 3. Weibull plots of turbine blade set removal time for high-pressure turbine $T-1$ blade sets from field data where $N_{\text {eng }}=16$. Number of $T-1$ turbine blades to a set, $n=82$. (a) Flight hours. (b) Flight cycles.

Theoretically, the time to failure of a turbine blade set is the time at which the first blade in the set fails regardless of the cause. This is analogous to a weak link in a chain. The chain is failed when the first link fails. The problem is that we do not know when the first blade failed nor do we know for sure the time when the most recent blade failure in a particular blade set has occurred. For purpose of the analysis, assume that the most recent blade that has failed in a set fails at the time the set is removed from the engine (Table 2, Time of removal, cycles). From this assumption, we need to determine the time at which the first blade has failed. We assumed the following scenario:

The set starts out with all new (unused) blades.

The reliability, $\boldsymbol{S}(\boldsymbol{t})$, of the last blade that fails is

$$
S(t)=1-F(t)
$$

In this calculation, the reliability, $\boldsymbol{S}(\boldsymbol{t})$ was estimated from the median rank of the failures, according to Eq. (9), ${ }^{21}$ where $\boldsymbol{i}$ is the failure number and $\boldsymbol{n}$ is the number of individual blades in a set (in this case, $\boldsymbol{n}=82$ ):

$$
\boldsymbol{F} \approx \frac{\boldsymbol{i}-0.3}{\boldsymbol{n}+0.4}
$$




\section{DRAFT}

Although the time of the last failure in a blade set cannot be known with any reasonable certainty, it can be assumed to have occurred at or shortly before the blade set is removed from service. The time of removal of a blade set is obtained from Table 2. Also, the number of failures in each engine blade set is given in Table 2. As an example, for engine number 2B, the time of removal $\boldsymbol{L}$ is 1404 cycles and there are $\boldsymbol{n}_{\text {blade }}=5$ failures within the blade set.

It is assumed for purposes of calculation that when the first blade failure in a blade set occurs, the blade set is no longer fit for its intended purpose even though it is still functioning. Accordingly, estimation of the time of the first failure in the blade set is a precondition for determining turbine blade life. In order to accomplish this task, it is first necessary to determine the probability of failure out of a large blade population that the most recent failure in the blade set represents. For engine number 2B, solving for $\boldsymbol{F}$ in Eq. (9), where $\boldsymbol{i}=5$ and $\boldsymbol{n}=82$,

$$
\boldsymbol{F}=(5-0.3) /(82+0.4)=0.057
$$

From Eq. (8),

$$
\boldsymbol{S}=1-0.057=0.943
$$

From the field data (Table 2, engine 2B), the time of removal of the blade set is 1404 cycles. From the Weibull plot of Fig. 3(b), a Weibull slope $\boldsymbol{e}$ equal to 5.984 is obtained. These Weibull parameters are substituted in Eq. (1) to solve for the characteristic life, $\boldsymbol{L}_{\beta}$, of the blades for engine 2B, which is $\boldsymbol{L}_{\beta}=2255$ cycles.

Again referring to Eq. (9), the value for $\boldsymbol{F}$ of the first failure in that blade set is determined. For $\boldsymbol{i}=1, \boldsymbol{F}=$ 0.0085. From Eq. (8), $\boldsymbol{S}=0.9915$. Substituting the value for $\boldsymbol{S}$ together with the Weibull slope $\boldsymbol{e}=5.984$ and $\boldsymbol{L}_{\beta}=$ 2255 in Eq. (1), the estimated time to the first failure is determined to be 1017 cycles. These calculations were repeated for each engine blade set. The resulting values are summarized in the last column of Table 2.

A Weibull plot of the estimated time to first failure of each of the $N_{\text {eng }}=16$ blade sets is shown in Fig. 4 and is compared with the time of blade set removal from Fig. 3(b). The Weibull parameters for Fig.4, "Time to first blade failure" are summarized in Table 3. The mean time of the turbine blade set, $\boldsymbol{L}_{\mathbf{m}}$ blade set, of 1482 cycles ( $\left.7016 \mathrm{hr}\right)$, is based on the first turbine blade failure and is approximately 26 percent less than the average blade set removal time. 


\section{DRAFT}

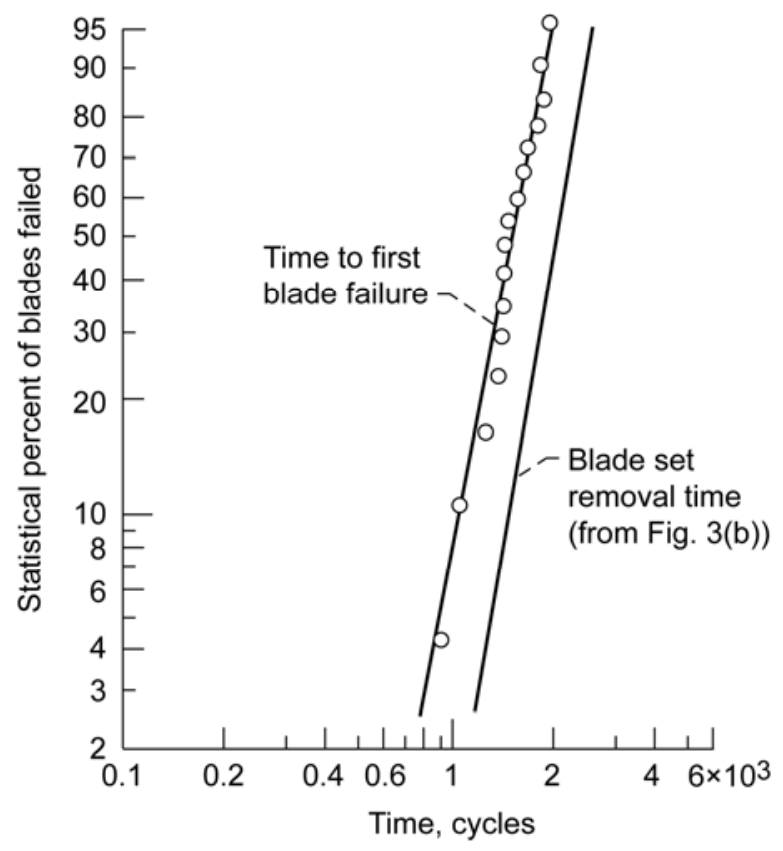

Figure 4. Estimated time to first blade failure in set compared to blade set removal time. Number of $\mathrm{T}-1$ turbine blades to a set, 82 .

Table 3. Summation of Lives of $\mathrm{T}-1$ Turbine Blade Sets and Individual Blades Based on Failure Mode Using Johnson-Weibull Analysis

\begin{tabular}{|c|c|c|c|c|c|c|c|}
\hline \multirow[t]{3}{*}{$\begin{array}{c}\text { Weibull } \\
\text { Parameters }\end{array}$} & \multicolumn{3}{|c|}{$\begin{array}{c}\text { Blade set life } \\
\text { (from Table 2 data) }\end{array}$} & \multicolumn{4}{|c|}{$\begin{array}{l}\text { Individual blade life based on failure mode, } \\
\text { cycles }\end{array}$} \\
\hline & \multicolumn{2}{|c|}{ Time of removal } & \multirow{2}{*}{$\begin{array}{c}\text { Estimated } \\
\text { time to first } \\
\text { blade failure, } \\
\text { cycles }\end{array}$} & \multirow{2}{*}{$\begin{array}{l}\text { All failure } \\
\text { modes }\end{array}$} & \multirow[t]{2}{*}{ Oxidation/erosion } & \multirow{2}{*}{$\begin{array}{c}\text { Thermal-mechanical } \\
\text { fatigue }\end{array}$} & \multirow[t]{2}{*}{ Other } \\
\hline & $\mathrm{hr}$ & cycles & & & & & \\
\hline 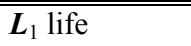 & 43337 & 993 & 668 & 1550 & 2093 & 2113 & 1717 \\
\hline $\boldsymbol{L}_{5}$ life & 5873 & 1304 & 912 & 2116 & 2857 & 2884 & 2343 \\
\hline$L_{10}$ life & 6714 & 1471 & 1046 & 2427 & 3278 & 3309 & 2688 \\
\hline $\boldsymbol{L}_{50}$ life & 9529 & 2015 & 1499 & 3478 & 4698 & 4742 & 3852 \\
\hline Mean life & ${ }^{\mathrm{b}} 9406$ & ${ }^{\mathrm{c}} 1987$ & ${ }^{d} 1482$ & $\mathrm{~d}_{3434}$ & ${ }^{\mathrm{d}} 4638$ & $\mathrm{~d}_{4582}$ & $\mathrm{~d}_{3803}$ \\
\hline${ }^{\mathrm{a}} \boldsymbol{L}_{\beta}$ & 10201 & 2142 & 1608 & 3731 & 5039 & 5086 & 4132 \\
\hline Weibull slope & 5.379 & 5.984 & 5.235 & 5.235 & 5.235 & 5.235 & 5.235 \\
\hline
\end{tabular}

${ }^{a}$ Life at a 63.2 percent probability of failure, characteristic life

${ }^{\mathrm{b}}$ Life at a 47.6 percent probability of failure

${ }^{c}$ Life at a 47.2 percent probability of failure

${ }^{\mathrm{d}}$ Life at a 47.7 percent probability of failure

These lives are summarized in Table 3. There is an insignificant difference in the Weibull slopes between the two Weibull plots. For purposes of comparison, the slope of 5.984 derived from the time of removal in cycles was used. 


\section{DRAFT}

\section{E. Turbine Blade Life}

Knowing the life of the blade set based on the estimated time to the first failure on each blade set, it is possible to determine the distributive lives of the individual blades from Eq. (6). It is assumed that the Weibull slope for each of the individual blades is identical to the Weibull slope for the blade sets based on the time to first failure from Fig. 4 and equals 5.235.

Based on the characteristic life, $\boldsymbol{L}_{\beta}$, for the blade set of 1608 cycles (see Table 3 column, "Estimated time to first blade failure"), the calculated characteristic life, $\boldsymbol{L}_{\beta}$, for the individual blade is 3731 cycles (see Table 3 column, “All failure modes").

From Eq. (1) all the other blade lives for each probability of failure (survival) can be calculated. These results are summarized in Table 3 and are represented by the Weibull plot in Fig. 5 labeled "Individual blade life." The mean individual blade life, $\boldsymbol{L}_{\mathbf{m}}$ blade, is 3434 cycles $(16256 \mathrm{hr})$, or approximately 2.3 times the mean life of the blade set, $\boldsymbol{L}_{\mathbf{m}}$ blade set, of 1480 cycles $(7008 \mathrm{hr})$. The $\boldsymbol{L}_{\mathbf{1 0}}$ individual blade life calculated from Johnson-Weibull analysis is 2427 cycles $(11077 \mathrm{hr})$ compared to 1046 cycles (4774 hr) for the blade set. The life of the blade set will always be less than the life of an individual blade at the same probability of survival (failure).

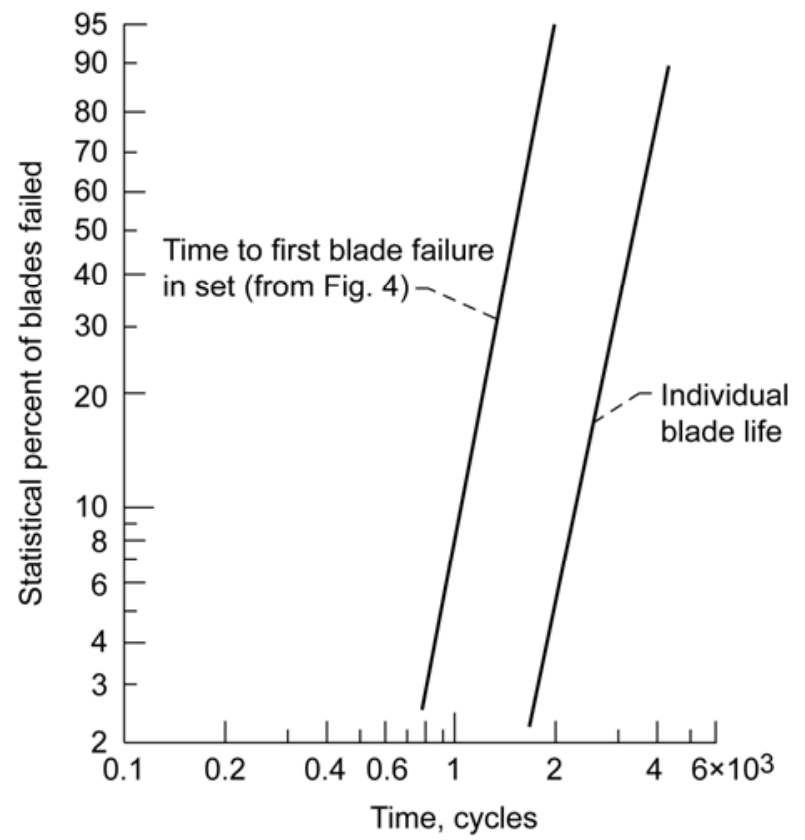

Figure 5. Calculated individual turbine $T-1$ blade life from estimated time to first blade failure in blade set. Number of $T-1$ turbine blades to a set, 82 .

\section{F. Failure Mode}

The time of removal of the blade sets together with the cataloged failure mode of those blades in each set that failed is summarized in Table 2. As previously discussed, the blades were first inspected for thermal-mechanical fatigue (TMF). If cracks were evident on the blade even if other failure modes were also evident, the cause for removal was cataloged as TMF. The remaining blades were inspected for oxidation/erosion $(\mathrm{O} / \mathrm{E})$. As with those blades cataloged as being failed by TMF, those blades that exhibited O/E damaged were so cataloged even where 


\section{DRAFT}

damage from other failure modes were manifested on the blade. The remaining blades were examined for damage for the other causes. These other causes were not identified; the cause was categorized and cataloged as "Other." The "Other" category can include creep (stress rupture), yield, fracture mechanics (flaw initiated crack), fretting (wear and fatigue), corrosion, foreign object damage (FOD), and wear (blade tip rub).

There were 111 cataloged blade failures out of a total of 1312 blades (Table 2). The failed blades comprised 8.5 percent of the total number of blades in the 16 blade sets. Thermal-mechanical fatigue accounted for approximately 20 percent of the failures, or 1.7 percent of the blade population. Oxidation/erosion accounted for approximately 21 percent of the failures, or 1.75 percent of the blade population. The highest accounting for blade failures occurs under the "Other" category. This is approximately 59 percent of the failures, or 5 percent of the blade population.

With reference to the strict-series system reliability equation (Eq. (5)), the resulting blade lives associated with the various failure modes with respect to the actual blade life can be derived from the Lundberg-Palmgren model for system failure ${ }^{13}$ and are expressed by Johnson ${ }^{10}$ as follows:

$$
\boldsymbol{X}=\frac{\boldsymbol{L}_{\mathrm{blade}}^{e}}{\boldsymbol{L}_{\mathrm{fm}}^{e}}
$$

where $\boldsymbol{X}$ is the fractional percent of components failed from a cataloged failure mode, $\boldsymbol{L}_{\mathrm{blade}}$ is the individual blade life, and $\boldsymbol{L}_{\mathrm{fm}}$ is the individual blade life resulting from a cataloged failure mode (fm). If each blade failure due to a cataloged failure mode is known as a percentage of the total number of failed blades, then the life of the blade related to that failure mode can be determined from Eq. (11) and vice versa. However, a condition precedent for using Eq. (11) is that the individual Weibull slopes must be known or assumed with reasonable engineering and statistical certainty.

The results of this analysis are shown in Fig. 6 and summarized in Table 3. The resulting blade life attributed

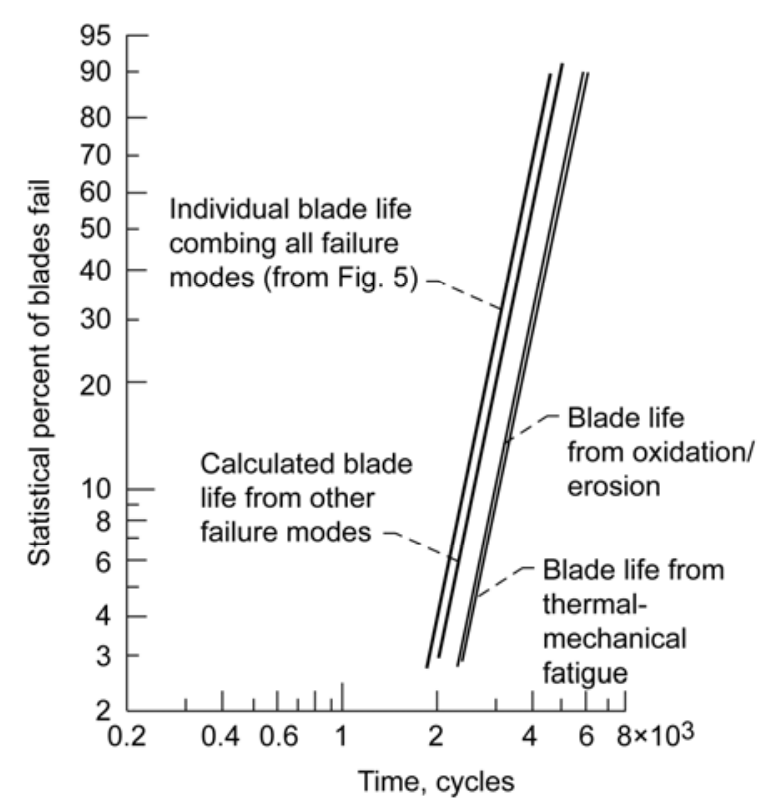

Figure 6. Turbine $\mathrm{T}-1$ blade life based on failure mode. 


\section{DRAFT}

to oxidation/erosion equaled that attributed to thermal-mechanical fatigue. The category that contributed most to blade life was "Other." In other words, if for any reason there were no blade failures attributed to oxidation/erosion and thermal-mechanical fatigue, the overall blade $\boldsymbol{L}_{\mathbf{1 0}}$ life would increase from 2427 cycles to 2688 cycles, or approximately 11 percent. Because of statistical variance, this increase in life would probably never be noticed in an actual application.

Referring to engine number $6 \mathrm{~B}$ in Table 2 , there are 40 failures attributed to "Other" and a single failure attributed to thermal-mechanical fatigue. Assume for purposes of discussion that at a time of 1843 cycles (from Table 2, engine 6B) a single blade failed from thermal-mechanical fatigue and broke loose, causing secondary damage to 40 other blades in the set. The estimated time to first blade failure for engine $6 \mathrm{~B}$ would change from 886 cycles to 1843 cycles.

A Weibull analysis of the data was performed with the revised life value $(1843$ cycles $)$ for engine blade set 6B. From recalculation of the data, the Weibull slope was increased from 5.235 to 6.237 and the blade $\boldsymbol{L}_{\mathbf{1 0}}$ life was decreased from 2427 cycles to 2339 cycles. These changes are considered insignificant.

If the 40 blade failures cataloged under "Other" for engine blade set 6B in Table 2 are discarded, the number of failed blades categorized under "Other" for engine blade set $6 \mathrm{~B}$ is reduced from 66 to 26 . This will reduce the total number of failed blades in Table 2 from 111 to 71 . The failed blade fractions for 71 failed blades for the three categories become $0.324,0.31$, and 0.366 , for Oxidation/Erosion (O/E), TMF, and "Other," respectively.

The respective blade $\boldsymbol{L}_{\mathbf{1 0}}$ life for each failure category in Table 3 was recalculated using Eq. (11) based on a Weibull slope $\boldsymbol{e}=6.237$ and the revised blade $\boldsymbol{L}_{\mathbf{1 0}}$ life of 2339 cycles. For the blade life based on oxidation/erosion, the $\boldsymbol{L}_{\mathbf{1 0}}$ life decreased from 3278 cycles to 2802 cycles. For thermal-mechanical fatigue, the $\boldsymbol{L}_{\mathbf{1 0}}$ life decreased from 3278 to 2748 cycles. However, for the failure modes cataloged under "Other," the $\boldsymbol{L}_{\mathbf{1 0}}$ life increased from 2688 to 2822 cycles. In this scenario, if the failure modes related to oxidation/erosion and thermal-mechanical fatigue are eliminated, the blade $\boldsymbol{L}_{\mathbf{1 0}}$ life would be increased from 2339 to 2748 cycles, or approximately 17 percent. Again, as before, this increase in life would probably never be noticed in an actual application.

\section{G. Simplified Life Formula}

As previously discussed, there are competing failure modes that affect turbine blade life. Because of this, there was no attempt to analytically perform a life analysis based on any single failure mode to compare with the results presented. We are unaware of any published analysis of the turbine blades discussed in this paper. However, it is 


\section{DRAFT}

possible based on the work presented herein to develop a simplified equation that will allow the user airline to estimate the life of their turbine blades for purpose of maintenance and replacement.

Of the failure modes discussed, it is our opinion that only the failure mode associated with low-cycle fatigue (i.e., thermal-mechanical fatigue (TMF)) can be measured in terms of cycles to failure with reasonable engineering certainty. High-cycle fatigue is related to the frequency of cycling, which is variable based upon gas velocity and thermal fluctuation. Also, the rate of cycling cannot be assumed with any reasonable engineering certainty much less measured. A prudent approach to the problem of high-cycle fatigue as it relates to a turbine blade application would be to assume that it is time dependent for a given engine application and operating profile. All the other failure modes discussed are also assumed to be time dependent for a given engine application and operating profile.

From Johnson ${ }^{10}$ the mean time to failure or removal is a function of the Weibull slope $\boldsymbol{e}$. From the Weibull analysis summarized in Table 3, for a Weibull slope $\boldsymbol{e}$ of 5.379, the mean time to blade set removal $\left(\boldsymbol{L}_{\mathrm{m} \text { blade set }}\right)$ is 9406 (1987 cycles). This occurs at a 47.6 percent probability of failure. The mean time per cycle is equal to 4.74 hr/cycle (9406 hr, or 1987 cycles).

For purposes of comparison, as the dispersion or scatter in the data increases, the Weibull slope $\boldsymbol{e}$ decreases. ${ }^{10}$ As an example, for a normal distribution where the mean time to failure occurs at a 50 percent probability of failure, the Weibull slope $\boldsymbol{e}$ equals 3.57. For a Rayleigh distribution where the Weibull slope $\boldsymbol{e}$ equals 2, the probability of failure is 54.4 percent. For an exponential distribution, the probability of failure is 63.2 percent at a Weibull slope $\boldsymbol{e}$ equal to 1. From this trend, an empirical formula can be derived as follows:

$$
\boldsymbol{F}_{\mathrm{m}} \approx 0.621 \boldsymbol{e}^{-0.172}
$$

where $\boldsymbol{F}_{\mathrm{m}}$ is the mean probability of failure as a fractional percent and $\boldsymbol{e}$ is the Weibull slope. From Eq. (1),

$$
\ln \ln \left[\frac{1}{\left(1-\boldsymbol{F}_{\mathrm{m}}\right)}\right]=\boldsymbol{e} \ln \left[\frac{\boldsymbol{L}_{\mathrm{M}}}{\boldsymbol{L}_{\beta}}\right]
$$

or

$$
\boldsymbol{L}_{\mathbf{M}}=\boldsymbol{L}_{\beta} \ln \left[\frac{1}{\left(1-\boldsymbol{F}_{\mathbf{m}}\right)}\right]^{(1 / \boldsymbol{e})}
$$

where $\boldsymbol{L}_{\mathbf{M}}$ is the mean time to removal and $\boldsymbol{L}_{\boldsymbol{\beta}}$ is the characteristic life or the life at a 63.2 percent probability of failure. 


\section{DRAFT}

From Table 2, the summation of the time of removal of the blade sets divided by the number of blade sets equals the numerical average of the time of blade set removal ( $\left.\boldsymbol{L}_{\text {avg-blade set }}\right)$ where $\boldsymbol{L}_{\text {avg-blade set }}=9421 \mathrm{hr}(1990$ cycles $)$. This numerical average of $9421 \mathrm{hr}$ (1990 cycles) correlates to the mean value from the Weibull analysis of $9406 \mathrm{hr}$ (1987 cycles) summarized in Table 3 . Accordingly, the numerical average of the blade set removal time

( $\left.\boldsymbol{L}_{\text {avg-blade set }}\right)$ can be substituted for the mean time to blade set removal ( $\boldsymbol{L}_{\mathbf{m}}$ blade set $)$ from the Weibull analysis in further calculations.

From Table 3 (column, "Estimated time to first failure"), the mean time to first blade failure in a set is 1480 cycles, or $7015 \mathrm{hr}(1480$ cycles $\times 4.74 \mathrm{hr} /$ cycle $)$. The mean time, $\boldsymbol{L}_{\mathrm{m}}$ blade to first blade failure in a set in terms of the average blade set time to removal is

$$
\boldsymbol{L}_{\mathrm{m} \text { blade }}=(7015 \mathrm{hr} / 9406 \mathrm{hr}) \boldsymbol{L}_{\text {avg-blade set }}=0.742 \boldsymbol{L}_{\text {avg-blade set }}
$$

An acceptable failure rate needs to be established for blade removal. As discussed, 111 blades ( 8.5 percent) failed of the 1312 blades comprising the 16 blade sets. It is therefore assumed that that a 10-percent failure rate $\left(\boldsymbol{L}_{\mathbf{1 0}}\right)$ would be acceptable as an upper failure limit. From Fig. 2 and Eq. (1),

$$
\frac{\ln \ln \left(\mathbf{1} / \boldsymbol{S}_{2}\right)-\ln \ln \left(\mathbf{1} / \boldsymbol{S}_{1}\right)}{\ln \boldsymbol{L}_{2}-\ln \boldsymbol{L}_{1}}=\boldsymbol{e}
$$

This reduces to

$$
\left[\ln \left(1 / \boldsymbol{S}_{1}\right) / \ln \left(1 / \boldsymbol{S}_{2}\right)\right]=\left[\boldsymbol{L}_{1} / \boldsymbol{L}_{2}\right]^{\mathbf{e}}
$$

In Eq. (14b), let

$$
\begin{gathered}
\boldsymbol{S}_{1}=\boldsymbol{S}_{90}=0.90 \\
\boldsymbol{S}_{2}=\boldsymbol{S}_{\mathbf{m}}=(1-0.477)=0.523 \\
\boldsymbol{L}_{1}=\boldsymbol{L}_{\mathbf{1 0}}
\end{gathered}
$$

and from Eq. (12)

$$
\boldsymbol{L}_{2}=\boldsymbol{L}_{\mathbf{m}}=0.742 \boldsymbol{L}_{\text {avg-blade set }}
$$




\section{DRAFT}

where

$$
\boldsymbol{L}_{\text {avg-blade set }}=(\text { Sum of time to removal of blade sets }) /(\text { number of blade sets })
$$

Substituting the above values into Eq. (14b) and solving for the $\boldsymbol{L}_{\mathbf{1 0}}$ blade set life for time to first blade failure in a set where Weibull slope $\boldsymbol{e}=5.235$ (from Fig. 4),

$$
\begin{aligned}
\boldsymbol{L}_{\mathbf{1 0} \text { blade set }}= & 0.742 \boldsymbol{L}_{\text {avg-blade set }}\left[\ln \left(1 / \boldsymbol{S}_{1}\right) / \ln \left(1 / \boldsymbol{S}_{2}\right)\right]^{1 / \mathbf{e}} \\
& =0.742 \boldsymbol{L}_{\text {avg-blade set }}[\ln (1 / 0.90) / \ln (1 / 0.523)]^{1 / 5.235} \\
& =0.524 \boldsymbol{L}_{\text {avg-blade set }}
\end{aligned}
$$

Combining Eqs. (3) and (14), the following empirical equation for the $\boldsymbol{L}_{\mathbf{1 0}}$ individual blade life can be written:

$$
\boldsymbol{L}_{10 \text { blade }}=0.524 \boldsymbol{L}_{\text {avg-blade set }}(\boldsymbol{n})^{1 / \boldsymbol{e}}=0.524 \boldsymbol{L}_{\text {avg-blade set }}(\boldsymbol{n})^{0.191}
$$

Equation (16a) can be further simplified where

$$
\boldsymbol{L}_{10 \text { blade }} \approx\left(\boldsymbol{L}_{\text {avg-blade set }} / 2\right)(\boldsymbol{n})^{0.2}
$$

Substituting $\boldsymbol{L}_{\text {avg-blade set }}=1989$ cycles and $\boldsymbol{n}=82$ into Eqs. (15a) and (15b), $\boldsymbol{L}_{\mathbf{1 0} \text { blade }}=2418$ and 2401 cycles, respectively. This correlates to the individual blade $\boldsymbol{L}_{\mathbf{1 0}}$ blade life from Table 3 of 2427 cycles. Assuming a Weibull slope of 5.235, the value of the characteristic life $\boldsymbol{L}_{\beta}$ for individual blades can be calculated from Eq. (1). Knowing $\boldsymbol{L}_{\beta}$, the individual blade life at any reliability (probability of survival, $\boldsymbol{S}$ ) can be calculated from Eq. (1).

\section{Summary of Results}

Sixteen high-pressure turbine (HPT) T-1 blade sets were removed from commercial aircraft engines that had been commercially flown by a single airline. Each blade set contained 82 blades. These engines were brought to the maintenance shop for refurbishment or overhaul. The blades on each HPT T-1 blade set were removed and inspected for damage. The damage found was cataloged into three categories related to their mode of failure. These were (1) Thermal-mechanical fatigue, (2) Oxidation/Erosion, and (3) Other. From these field data, the turbine blade life was determined as well as the lives related to individual blade failure modes using Johnson-Weibull analysis. 


\section{DRAFT}

From these data and analysis, a simplified formula for calculating turbine blade life and reliability was formulated. The following results were obtained:

1. The following empirical equation for the $\boldsymbol{L}_{\mathbf{1 0}}$ individual blade life was formulated:

$$
\boldsymbol{L}_{\mathbf{1 0} \text { blade }} \approx\left(\boldsymbol{L}_{\text {avg-blade set }} / 2\right)(\boldsymbol{n})^{0.2}
$$

where $\boldsymbol{L}_{\text {avg-blade set }}=$ (Sum of time to removal of blade sets)/(number of blade sets) and $\boldsymbol{n}$ is the number of blades in a set.

2. The individual blade life, $\boldsymbol{L}_{\mathbf{1 0}}$ blade, calculated from Johnson-Weibull analysis is 2427 cycles (11 $\left.077 \mathrm{hr}\right)$ compared to $\boldsymbol{L}_{\mathbf{1 0}}$ blade set life of 1046 cycles ( $4774 \mathrm{hr}$ ). The life of the blade set (blade set life is defined as the failure time of first blade in a blade set) will always be less than the life of an individual blade at any given probability of survival (failure).

3. The resulting individual blade life attributed to oxidation/erosion equaled that attributed to thermal mechanical fatigue. The category that contributed most to individual blade failure was "Other" that includes creep (stress rupture), yield, fracture mechanics (flaw initiated crack), fretting (wear and fatigue), corrosion, foreign object damage (FOD), and wear (blade tip rub).

4. If there were no blade failures attributed to oxidation/erosion and thermal/mechanical fatigue, the overall individual blade life, $\boldsymbol{L}_{\mathbf{1 0} \text { blade }}$, would increase approximately 11 to 17 percent.

\section{References}

${ }^{1}$ Zaretsky, E. V., Hendricks, R. C., and Soditus, S. M., "Weibull-Based Design Methodology for Rotating Structures in Aircraft Engines," International Jour. Rotating Machinery, Vol. 9, 2003, pp. 313-325.

${ }^{2}$ Davis, D. Y., and Stearns, E. M., "Energy Efficient Engine Flight Propulsion System Final Design and Analysis,” NASA CR-168219, 1985.

${ }^{3}$ Halila, E. E., Lenahan, D. T., and Thomas, T. T., "Energy Efficient Engine High Pressure Turbine Test Hardware: Detailed Design Report,” NASA CR-167955. 1982.

${ }^{4}$ Manson, S. S., and Halford, G. R., Fatigue and Durability of Structural Materials, ASM International, Materials Park, Ohio, 2006, p. 401.

${ }^{5}$ Sawyer, J. W., ed., Gas Turbine Engineering Handbook, Gas Turbine Publications, Inc., Stamford, CT, 1966. 


\section{DRAFT}

${ }^{6}$ Nelson, W., Applied Life Data Analysis, John Wiley \& Sons, NY, 1982., p. 407.

${ }^{7}$ Weibull, W., A Statistical Theory of the Strength of Materials, Ingeniors Vetenskaps Akademien-Handlinger, No. $151,1939$.

${ }^{8}$ Weibull, W., The Phenomenon of Rupture in Solids, Ingeniors Vetenskaps Akademien-Handlinger, No. $153,1939$.

${ }^{9}$ Weibull, W., “A Statistical Distribution of Wide Applicability,” J. Appl. Mech., ASME Trans., Vol. 18, No. 3, 1951, pp. 293-297.

${ }^{10}$ Johnson, L. G., The Statistical Treatment of Fatigue Experiments, Elsevier Publishing Co. Amsterdam, The Netherlands, 1964.

${ }^{11}$ Cetal, A. D., and Duhl, D. N., "Second-Generation Nickel-Based Single Crystal Superalloy," Proc. Sixth International Symposium Superalloys, High Temperature Alloys Committee, The Metallurgical Society, Sept. 18-22, 1988, Seven Springs Mountain Resort, Champion, PA.

${ }^{12}$ Melis, M. E., Zaretsky, E.V., and August, R., "Probabilistic Analysis of Aircraft Gas Turbine Disk Life and Reliability,” J. Propulsion and Power, AIAA Trans., 15, Sept.-Oct. 1999, pp. 658-666.

${ }^{13}$ Lundberg, G., and Palmgren, A., "Dynamic Capacity of Rolling Bearings," Acta Polytechnica, Mechanical Engineering Series, Vol. 1, No. 3, Stockholm, 1947.

${ }^{14}$ Burrow, M. F., Thomas, D., Swain, M. V. and Tyas, M. J., “Analysis of Tensile Bond Strengths Using Weibull Statistics,” Biomaterials, Vol. 25, No. 20, 2004, pp. 5031-5035.

${ }^{15}$ Ellis, F. V., and Tordonato, S., "Failure Analysis and Life Assessment Studies for Boiler Tubes," ASME Pressure Vessels and Piping Division Publication, Vol. 392, 1999, pp. 3-13.

${ }^{16}$ Tomimatsu, M., Sakai, M., and Kikuchi, M., "Fracture Toughness Evaluation Based on Master Curve Procedure,” ASME Pressure Vessels and Piping Division Publication, Vol. 390, 1997, pp. 343-348.

${ }^{17}$ Osborne, N. G., Graves, G. G., and Ferber, M. K., "Dynamic Fatigue Testing of Candidate Ceramic Materials for Turbine Engines to Determine Slow Crack Growth Parameters,” Jour. Engr. for Gas Turbine and Power, ASME Trans., Vol. 119, No. 2, Apr. 1997, pp. 273-278.

${ }^{18}$ Ostojic, P., and Berndt, C. C., "Variability in Strength of Thermally Sprayed Coatings," Surf. Coat. Technol., Vol. 34, No. 1, 1987, pp. 43-50.

${ }^{19}$ Holland, F. A., and Zaretsky, E. V., "Investigation of Weibull Statistics in Fracture Analysis of Cast Aluminum,” Jour. Mech. Des., ASME Trans., Vol. 112, No. 2, 1990, pp. 246-254.

${ }^{20}$ Williams, S., and Fec, M. C., Weibull Analysis of Reconditioned Railroad Roller Bearing Life Test Data, ASME Rail Transportation Division Publication, Vol. 5, 1992, pp. 83-87.

${ }^{21}$ Summers-Smith, J. D., Fault Diagnosis as an Aid to Process Machine Reliability," Quality and Reliability Engineering International, Vol. 5, No. 3, 1989, pp. 203-205. 


\section{DRAFT}

${ }^{22}$ Vlcek, B. L., Hendricks, R. C., Zaretsky, E. V., and Savage, M., Comparative Fatigue Lives of Rubber and PVC Wiper Cylindrical Coatings,” Tribology. Trans., Vol. 46, No. 1, 2003, pp. 101-110.

${ }^{23}$ Poplawski, J. V., Peters, S. M., and Zaretsky, E. V., Effect of Roller Profile on Cylindrical Roller Bearing Life Prediction Part I: Comparison of Bearing Life Theories, STLE Tribology Trans., Vol. 44, No. 3, 2001, pp. 339-350.

${ }^{24}$ Palmgren, A., "Die Lebensdauer von Kugellagern (The Service Life of Ball Bearings)," Zectsckrift des Vereines Deutscher Ingenieure, Vol. 68, No. 14, 1924, pp. 339-341. (NASA TT-F-13460, 1971.)

${ }^{25}$ Langer, B.F., "Fatigue Failure From Stress Cycles of Varying Amplitude," J. Appl. Mech., ASME Trans, Vol. 59, 1937, pp. A160-A162.

${ }^{26}$ Miner, M.A., "Cumulative Damage in Fatigue," J. Appl. Mech., ASME Trans., Vol. 12, No. 3, 1945, pp. A159-A164.

${ }^{27}$ Kapur, K. C. and Lamberson, L. R., Reliability in Engineering Design, John Wiley and Sons Inc., New York, 1977. 


\section{DRAFT}

\section{Appendix A \\ Derivation of Weibull Distribution Function}

According to Weibull ${ }^{7-9}$ and as presented in Ref. 12 (see also Ref. 23), any distribution function can be written as

$$
\boldsymbol{F}(\boldsymbol{X})=1-\exp \{-[\mathrm{f}(\boldsymbol{X})]\}
$$

where $\boldsymbol{F}(\boldsymbol{X})$ is the probability of an event (failure) occurring and $\mathrm{f}(\boldsymbol{X})$ is a function of an operating variable $\boldsymbol{X}$. Conversely, from Eq. (A1) the probability of an event not occurring (survival) can be written as

$$
1-\boldsymbol{F}(\boldsymbol{X})=\exp \{-[\mathrm{f}(\boldsymbol{X})]\}
$$

or

$$
1-\boldsymbol{F}=\exp \{-[\mathrm{f}(\boldsymbol{X})]\}
$$

where $\boldsymbol{F}=\boldsymbol{F}(\boldsymbol{X})$ and $(1-\boldsymbol{F})=\boldsymbol{S}$, the probability of survival.

If there are $\boldsymbol{n}$ independent components, each with a probability of the event (failure) not occurring $(1-\boldsymbol{F})$, the probability of the event not occurring in the combined total of all components can be expressed from equation (A2b) as

$$
(1-\boldsymbol{F})^{n}=\exp \{-[\boldsymbol{n f}(\boldsymbol{X})]\}
$$

Equation (A3) gives the appropriate mathematical expression for the principle of the weakest link in a chain or, more generally, for the size effect on failures in solids. The application of Eq. (A3) is illustrated by a chain consisting of several links. Testing finds the probability of failure $\boldsymbol{F}$ at any load $\boldsymbol{X}$ applied to a "single" link. To find the probability of failure $\boldsymbol{F}_{\boldsymbol{n}}$ of a chain consisting of $\boldsymbol{n}$ links, one must assume that if one link has failed the whole chain fails. That is, if any single part of a component fails, the whole component has failed. Accordingly, the probability of nonfailure of the chain $\left(1-\boldsymbol{F}_{n}\right)$, is equal to the probability of the simultaneous nonfailure of all the links. Thus,

$$
1-\boldsymbol{F}_{n}=(1-\boldsymbol{F})^{n}
$$

or 


\section{DRAFT}

$$
S_{n}=S^{n}
$$

Where the probabilities of failure (or survival) of each link are not necessarily equal (i.e., $\boldsymbol{S}_{1} \neq \boldsymbol{S}_{2} \neq \boldsymbol{S}_{3} \neq \ldots$ ), Eq. (A4b) can be expressed as

$$
\boldsymbol{S}_{n}=\boldsymbol{S}_{1} \cdot \boldsymbol{S}_{2} \cdot \boldsymbol{S}_{3} \cdot \ldots
$$

This is the same as Eq. (18) of the main text.

From Eq. (A3) for a uniform distribution of stresses $\boldsymbol{\sigma}$ throughout a volume $\boldsymbol{V}$,

$$
\boldsymbol{F}_{\boldsymbol{V}}=1-\exp \{-[\boldsymbol{V} \mathbf{f}(\boldsymbol{\sigma})]\}
$$

or

$$
\boldsymbol{S}=1-\boldsymbol{F}_{V}=\exp \{-[\boldsymbol{V} \mathbf{f}(\boldsymbol{\sigma})]\}
$$

Equation (A5b) can be expressed as follows:

$$
\ln \ln \left[\frac{1}{S}\right]=\ln \mathbf{f}(\sigma)+\ln V
$$

It follows that if $\ln \ln (1 / S)$ is plotted as the ordinate and $\ln f(\sigma)$ as the abscissa in a system of rectangular coordinates, a variation of volume $\boldsymbol{V}$ of the test specimen will imply only a parallel displacement but no deformation of the distribution function. Weibull ${ }^{6}$ assumed the form

$$
\mathbf{f}(\sigma)=\left[\frac{\sigma-\sigma_{\mathrm{u}}}{\sigma_{\beta}-\sigma_{\mathrm{u}}}\right]^{e}
$$

Where $\boldsymbol{e}$ is the Weibull slope, $\sigma$ is a stress at a given probability of failure, $\sigma_{\mathrm{u}}$ is a location parameter below which stress no failure will occur, and $\sigma_{\beta}$ is the characteristic stress at which 63.2 percent of the population will fail. Eq. (A6) becomes

$$
\ln \ln \left[\frac{1}{S}\right]=\boldsymbol{e} \ln \left(\sigma-\sigma_{\mathrm{u}}\right)-\boldsymbol{e} \ln \left(\sigma_{\beta}-\sigma_{\mathrm{u}}\right)+\ln \boldsymbol{V}
$$




\section{DRAFT}

If the location parameter $\sigma_{\mathbf{u}}$ is assumed to be zero, and $\boldsymbol{V}$ is normalized whereby $\ln \boldsymbol{V}$ is zero, Eq. (A8) can be written as

$$
\ln \ln \left[\frac{1}{S}\right]=\boldsymbol{e} \ln \left[\frac{\sigma}{\sigma_{\beta}}\right]\left(\sigma-\sigma_{\mathrm{u}}\right) \text { where } 0<\boldsymbol{\sigma}<\infty \text { and } 0<\boldsymbol{S}<1
$$

Equation (A9) is identical to Eq. (17) of the main text.

The form of Eq. (A9) where $\sigma_{\mathrm{u}}$ is assumed to be zero is referred to as "two-parameter Weibull."

Where $\sigma_{\mathrm{u}}$ is not assumed to be zero, the form of the equation is referred to as "three-parameter Weibull." 


\section{DRAFT}

\section{Appendix B-Derivation of Strict Series Reliability}

As discussed and presented in Refs. 12 and 23, G. Lundberg and A. Palmgren ${ }^{13}$ in 1947, using the Weibull equation (Appendix A) for rolling-element bearing life analysis, first derived the relationship between individual component lives and system life. The following derivation is based on but is not identical to the Lundberg-Palmgren analysis.

Referring to Fig. 2, from Eq. (A9) in Appendix A, the Weibull equation can be written as

$$
\ln \ln \left[\frac{1}{\boldsymbol{S}_{\mathrm{sys}}}\right]=\boldsymbol{e} \ln \left[\frac{\boldsymbol{L}}{\boldsymbol{L}_{\beta}}\right]
$$

where $\boldsymbol{L}$ is the number of cycles to failure.

Figure B.1 is a sketch of multiple Weibull plots where each Weibull plot represents a cumulative distribution of each component in the system. The system Weibull plot represents the combined Weibull plots 1, 2, 3, and so forth. All plots are assumed to have the same Weibull slope $e^{12}$ The slope $e$ can be defined as follows:

$$
\boldsymbol{e}=\frac{\ln \ln \left[\frac{1}{\boldsymbol{S}_{\mathrm{sys}}}\right]-\ln \ln \left[\frac{1}{\boldsymbol{S}_{\mathrm{ref}}}\right]}{\ln \boldsymbol{L}-\ln \boldsymbol{L}_{\mathrm{ref}}}
$$

or

$$
\frac{\ln \left[\frac{1}{S_{\mathrm{sys}}}\right]}{\ln \left[\frac{1}{\boldsymbol{S}_{\mathrm{ref}}}\right]}=\left[\frac{\boldsymbol{L}}{\boldsymbol{L}_{\mathrm{ref}}}\right]^{e}
$$

From Eqs. (B1) and (B2b), 


\section{DRAFT}

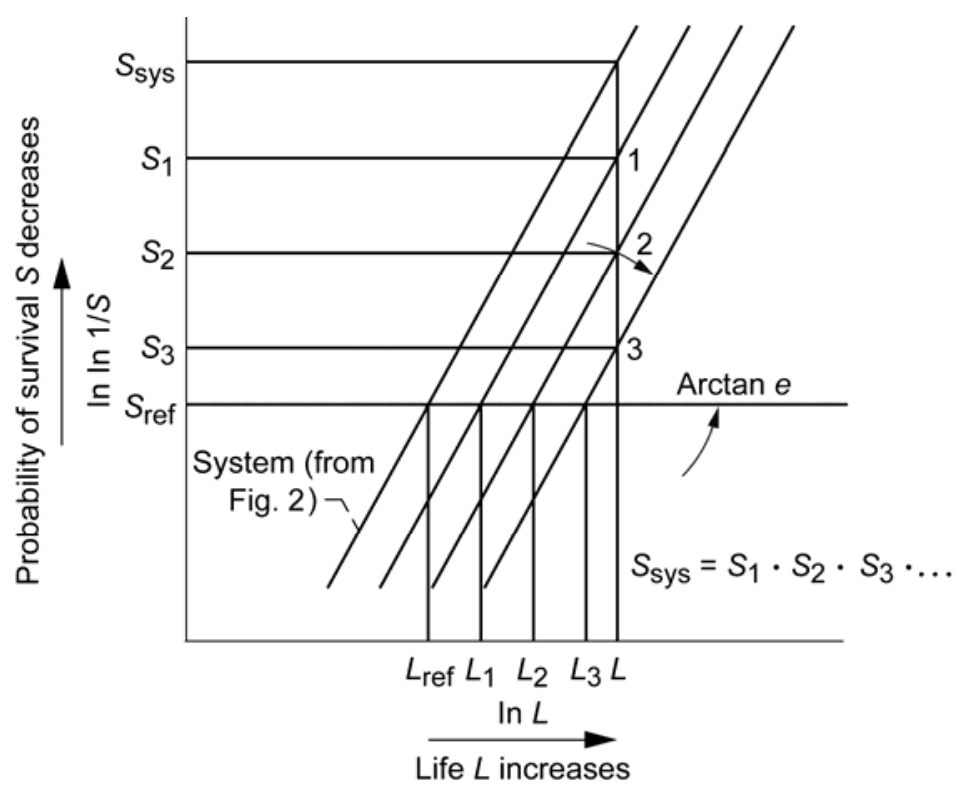

Figure B.1. Sketch of multiple Weibull plots where each numbered plot represents cumulative distribution of each component in system and system Weibull plot represents combined distribution of plots 1, 2, 3, etc. (all plots are assumed to have same Weibull slope $e$ ). ${ }^{12}$

$$
\ln \left[\frac{1}{\boldsymbol{S}_{\mathrm{sys}}}\right]=\left[\ln \frac{1}{\boldsymbol{S}_{\mathrm{ref}}}\right]\left[\frac{\boldsymbol{L}}{\boldsymbol{L}_{\mathrm{ref}}}\right]^{e}=\left[\frac{\boldsymbol{L}}{\boldsymbol{L}_{\beta}}\right]^{e}
$$

and

$$
\boldsymbol{S}_{\mathrm{sys}}=\exp \left\{-\left[\frac{\boldsymbol{L}}{\boldsymbol{L}_{\boldsymbol{\beta}}}\right]^{e}\right\}
$$

where $\boldsymbol{S}_{\text {sys }}=\boldsymbol{S}$ in Eq. (B1). For a given time or life $\boldsymbol{L}$, each component or stressed volume in a system will have a different reliability $\boldsymbol{S}$. From Eq. (A4c) for a series reliability system

$$
S_{\mathrm{sys}}=S_{1} \cdot S_{2} \cdot S_{3} \cdot \ldots
$$

Combining Eqs. (B4) and (B5) gives

$$
\exp \left\{-\left[\frac{\boldsymbol{L}}{\boldsymbol{L}_{\boldsymbol{\beta}}}\right]^{e}\right\}=\exp \left\{-\left[\frac{\boldsymbol{L}}{\boldsymbol{L}_{\beta 1}}\right]^{e}\right\} \times \exp \left\{-\left[\frac{\boldsymbol{L}}{\boldsymbol{L}_{\beta 3}}\right]^{e}\right\} \times \ldots
$$




\section{DRAFT}

$$
\exp \left\{-\left[\frac{\boldsymbol{L}}{\boldsymbol{L}_{\beta}}\right]^{e}\right\}=\exp \left\{-\left[\frac{\boldsymbol{L}}{\boldsymbol{L}_{\beta 1}}\right]^{e}+\left[\frac{\boldsymbol{L}}{\boldsymbol{L}_{\beta 2}}\right]^{e}+\left[\frac{\boldsymbol{L}}{\boldsymbol{L}_{\beta 3}}\right]^{e}+\ldots\right\}
$$

It is assumed that the Weibull slope $\boldsymbol{e}$ is the same for all components. From Eq. (B6b)

$$
-\left[\frac{\boldsymbol{L}}{\boldsymbol{L}_{\beta}}\right]^{e}=-\left\{\left[\frac{\boldsymbol{L}}{\boldsymbol{L}_{\beta 1}}\right]^{e}+\left[\frac{\boldsymbol{L}}{\boldsymbol{L}_{\beta 2}}\right]^{e}+\left[\frac{\boldsymbol{L}}{\boldsymbol{L}_{\beta 3}}\right]^{e}+\ldots\right\}
$$

Factoring out $\boldsymbol{L}$ from Eq. (B7a) gives

$$
\left[\frac{1}{\boldsymbol{L}_{\beta}}\right]^{e}=\left[\frac{1}{\boldsymbol{L}_{\beta 1}}\right]^{e}+\left[\frac{1}{\boldsymbol{L}_{\beta 2}}\right]^{e}+\left[\frac{1}{\boldsymbol{L}_{\beta 3}}\right]^{e}+\ldots
$$

From Eq. (B3) the characteristic lives $\boldsymbol{L}_{\beta 1}, \boldsymbol{L}_{\beta 2}, \boldsymbol{L}_{\boldsymbol{\beta} 3}$, etc., can be replaced with the respective lives $\boldsymbol{L}_{1}, \boldsymbol{L}_{2}, \boldsymbol{L}_{3}$, etc., at $\boldsymbol{S}_{\text {ref }}$ (or the lives of each component that have the same probability of survival $\boldsymbol{S}_{\text {ref }}$ ) as follows:

$$
\left[\ln \frac{1}{S_{\text {ref }}}\right]\left[\frac{1}{L_{\text {ref }}}\right]^{e}=\left[\ln \frac{1}{S_{\text {ref }}}\right]\left[\frac{1}{L_{1}}\right]^{e}+\left[\ln \frac{1}{S_{\text {ref }}}\right]\left[\frac{1}{L_{2}}\right]^{e}+\left[\ln \frac{1}{S_{\text {ref }}}\right]\left[\frac{1}{L_{3}}\right]^{e}+\ldots
$$

where, in general, from Eq. (B3)

$$
\left[\frac{1}{\boldsymbol{L}_{\beta}}\right]^{e}=\left[\ln \frac{1}{\boldsymbol{S}_{\mathrm{ref}}}\right]\left[\frac{1}{\boldsymbol{L}_{\mathrm{ref}}}\right]^{e}
$$

and

$$
\left[\frac{1}{\boldsymbol{L}_{\beta 1}}\right]^{e}=\left[\ln \frac{1}{\boldsymbol{S}_{\mathrm{ref}}}\right]\left[\frac{1}{\boldsymbol{L}_{1}}\right]^{e} \text {, etc. }
$$

Factoring out $\ln \left(1 / \boldsymbol{S}_{\text {ref }}\right)$ from Eq. (B8) gives

$$
\left[\frac{1}{\boldsymbol{L}_{\mathrm{ref}}}\right]=\left\{\left[\frac{1}{\boldsymbol{L}_{1}}\right]^{e}+\left[\frac{1}{\boldsymbol{L}_{2}}\right]^{e}+\left[\frac{1}{\boldsymbol{L}_{3}}\right]^{e}+\ldots\right\}^{1 / e}
$$




\section{DRAFT}

or rewriting Eq. (B10) results in

$$
\left[\frac{1}{L}\right]^{e}=\sum_{i=1}^{n}\left[\frac{1}{L_{i}}\right]^{e}
$$

Equations (B10) and (B11) are identical to Eq. (5) of the text.

Equation (B10) can also be rewritten as follows:

$$
1=\left\{\left[\frac{\boldsymbol{L}_{\mathrm{ref}}}{\boldsymbol{L}_{1}}\right]^{e}+\left[\frac{\boldsymbol{L}_{\mathrm{ref}}}{\boldsymbol{L}_{2}}\right]^{e}+\left[\frac{\boldsymbol{L}_{\mathrm{ref}}}{\boldsymbol{L}_{3}}\right]^{e}+\ldots\right\}
$$

From Eq. (B12) and according to Johnson ${ }^{10}$ the fraction of failures due to each cataloged failure mode of a component is expressed as

(1) Percent fraction of failures resulting from cataloged failure mode 1,

$$
\boldsymbol{X}_{1}=\left[\frac{\boldsymbol{L}_{\mathrm{ref}}}{\boldsymbol{L}_{1}}\right]^{e}
$$

(2) Percent fraction of failures resulting from cataloged failure mode 2,

$$
\boldsymbol{X}_{2}=\left[\frac{\boldsymbol{L}_{\mathrm{ref}}}{\boldsymbol{L}_{2}}\right]^{e}
$$

(3) Percent fraction of failures resulting from cataloged failure mode 3,

$$
\boldsymbol{X}_{3}=\left[\frac{\boldsymbol{L}_{\mathrm{ref}}}{\boldsymbol{L}_{3}}\right]^{e}
$$

The form of Eq. (B13) is the same as Eq. (11) of the text. Substituting Eq. (B13) into Eq. (B12),

$$
\boldsymbol{X}_{1}+\boldsymbol{X}_{2}+\boldsymbol{X}_{3}+\cdots=1
$$




\section{DRAFT}

From Eqs. (B13a) to (B13c), if the life of the component and the percent fraction of the total failures represented by each cataloged failure mode are known, the life of the component related to each cataloged failure mode can be calculated. Hence, by observation, it is possible to determine the failure modes of a component population and determine the components life related to each cataloged failure mode. (Refer to Eq. (11) of the text.) 


\section{DRAFT}

\section{Appendix C-Linear Damage Rule}

Most machine components are operated under combinations of variable loading and speed. Figure C.1 shows an example of a typical flight profile for a commercial flight with the time of each segment given.

Palmgren ${ }^{24}$ working with ball and roller bearings recognized that the variation in both load and speed must be accounted for in order to predict component life. Palmgren ${ }^{24}$ reasoned: "In order to obtain a value for a calculation, the assumption might be conceivable that (for) a bearing which has a life of $\boldsymbol{k}$ million revolutions under constant load at a certain rpm (speed), a portion $\boldsymbol{M} / \boldsymbol{k}$ of its durability will have been consumed. If the bearing is exposed to a certain load for a run of $\boldsymbol{M}_{1}$ million revolutions where it has a life of $\boldsymbol{k}_{1}$ million revolutions, and to a different load for a run of $\boldsymbol{M}_{2}$ million revolutions where it will reach a life of $\boldsymbol{k}_{2}$ million revolutions, and so on, we will obtain

$$
\frac{\boldsymbol{M}_{1}}{\boldsymbol{k}_{1}}+\frac{\boldsymbol{M}_{2}}{\boldsymbol{k}_{2}}+\frac{\boldsymbol{M}_{3}}{\boldsymbol{k}_{3}}+\ldots=1
$$

In the event of a cyclic variable load we obtain a convenient formula by introducing the number of intervals $p$ and designate $\boldsymbol{m}$ as the revolutions in millions that are covered within a single interval. In that case we have

$$
(\boldsymbol{p})\left(\frac{\boldsymbol{m}_{1}}{\boldsymbol{k}_{1}}+\frac{\boldsymbol{m}_{2}}{\boldsymbol{k}_{2}}+\frac{\boldsymbol{m}_{3}}{\boldsymbol{k}_{3}}+\ldots\right)=1
$$

where $\boldsymbol{k}$ still designates the total life in millions of revolutions under the load and rpm (speed) in question (and $\boldsymbol{M}=p \boldsymbol{m})$.

Equations (C1) and (C2) were independently proposed for conventional fatigue analysis by B. Langer ${ }^{25}$ in 1937 and M. Miner ${ }^{26}$ in 1945, 13 and 21 years after Palmgren ${ }^{24}$, respectively. The equation has been subsequently referred to as the linear damage rule or the Palmgren-Langer-Miner rule. For convenience, the equation can be written as follows:

$$
\frac{1}{L}=\frac{X_{1}}{L_{1}}+\frac{X_{2}}{L_{2}}+\frac{X_{3}}{L_{3}}+\ldots \frac{X_{k}}{L_{k}}
$$

and 


\section{DRAFT}

$$
\boldsymbol{X}_{1}+\boldsymbol{X}_{2}+\boldsymbol{X}_{3}+\ldots \boldsymbol{X}_{\boldsymbol{k}}=1
$$

where $\boldsymbol{L}$ is the total life in stress cycles or race revolutions, $\boldsymbol{L}_{1} \ldots \boldsymbol{L}_{\boldsymbol{k}}$ is the life at a particular load and speed in stress cycles or race revolutions, and $\boldsymbol{X}_{1} \ldots \boldsymbol{X}_{\boldsymbol{k}}$ is the fraction of total running time at load and speed. From Eq. (C1)

$$
M_{1}=X_{1} L, M_{2}=X_{2} L, M_{3}=X_{3} L, \ldots M_{k}=X_{k} L
$$

Because the flight profile is repeatable, e.g., Fig. C.1, it is reasonable to use the percent of time in each segment to determine engine component life using Eq. (C3).

Equation (C3) is the basis for most variable-load fatigue analysis and is used extensively in bearing life prediction.

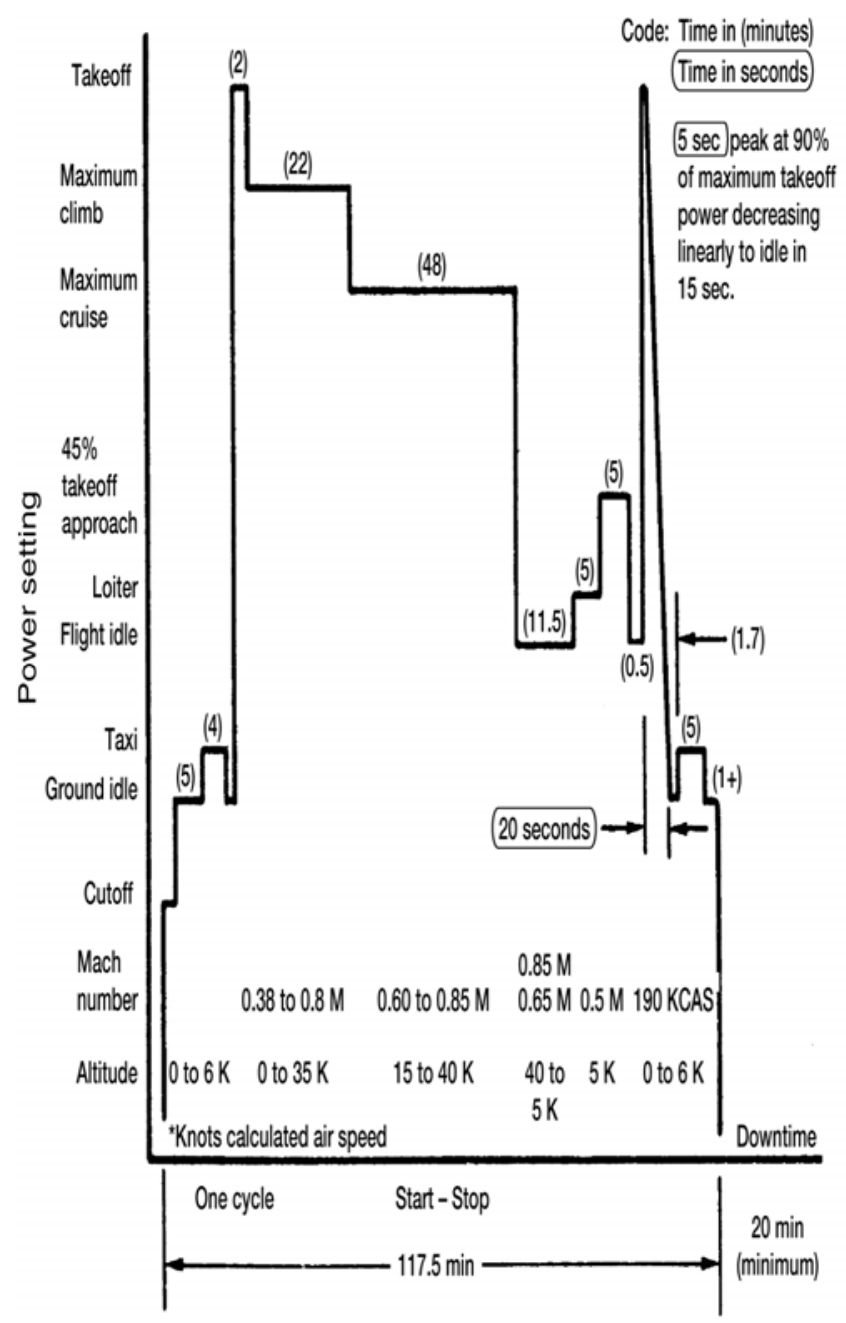

Figure C.1. Example typical flight profile. 